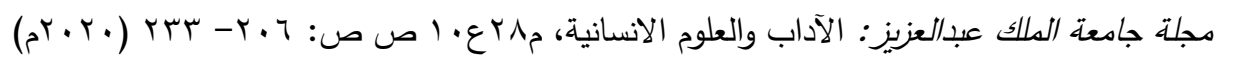
DOI:10.4197/Art.28-10.8

\title{
أثر القول بالنظرية النسبية على بعض المعتقدات عرض ونقد في ضوء عقيدة أهل السنة والجماعة
}

\section{د. أسماء سالم أحمد بن عفيف}

$$
\begin{aligned}
& \text { كلية الَد/ب والعلوم الإنسانية } \\
& \text { قسم الثربعة والدراسات الإسالامية - مسار العقيدة }
\end{aligned}
$$

مستخلص. ناقش بحث "أثر القول بالنظرية النسبية على بعض المعتقدات عرض ونقد" القبول الواسع الذي لاقته

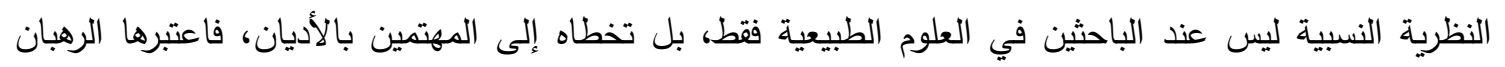
والمحاربون للإلحاد مناصرة ومريدة للتدين والإيمان بوجود الله. ولاقت كذلك رواجًا كثيرًا عند كثير من المهتمين بالبحث في العلوم الإسلامية فباتوا يقدمون تفسيرات لآيات القرآن الكريم وأحاديث النبي صلى الله عليه وسلم وبعض الغيبيات والعقائد من خلال ما توصلت إليه النظرية النسبية. فحاول البحث مناقشة هذا التوجه وأثثه على العقائد والمسلمات، وبيان وجه الصواب في التعامل مع المعتقدات والغيبيات.

وقد اشتمل البحث على مقدمة وثلاثة مباحث؛ ففي المقدمة حددت الباحثة أهميَّة الموضوع وأسباب اختياره، ومنهج البحث، وأما المبحث الأول فتعرض فيه للتعريف بأينشتاين صاحب النظرية النسبية حياته ونظريته، وقوانين هذه وفئه النظرية وفي المبحث الثاني تتاول البحث موقف لبعض آراء المفكرين والعلماء المسلمين من النظرية النسبية وفي

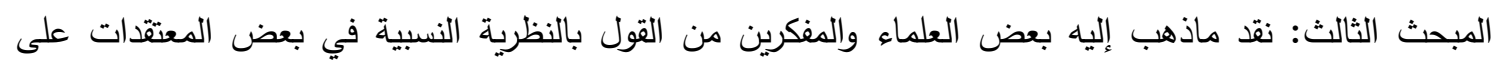
ضوء عقيدة أهل السنة والجماعة، حيث يشتمل على مطالب: المطلب الأول يتتاول قاعدة السلف في التعامل مع الأمور الغيبية. المطلب الثاني: الرد على دعاوى العلماء في الربط بين النظرية النسبية وعقيدة الإيمان بالملائكة. المطلب الثالث: الرد على دعاوى العلماء في الربط بين النظرية النسبية ووقوع معجزات الأنبياء.

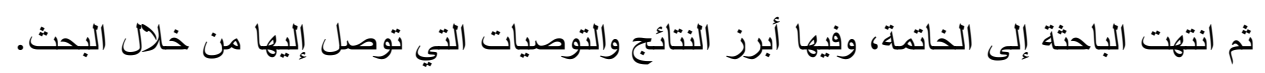


لكن ليس لحثّ الإسلام على العلم والبحثِ علاقة بربط النظريات الفيزيائية أو القوانين العلمية الطبيعية لإنيات بالآيات والأحاديث، فإن هذه النظريات والقيط القوانين محلٌّ للبحث والنقض، وما يثبته عالم قد يأتي آخر فرادي

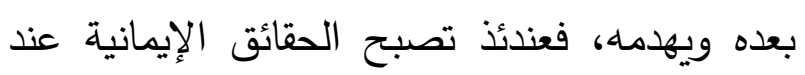
كثير من الناس - لا سيما أعداء الدعوة ممَّن يتصيدون الأخطاء - عرضةً للنقاش والأخذ والردّ. وإنما سبيل المؤمن مع آيات القرآن وأحاديث النبي لإلهي

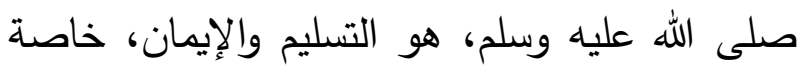

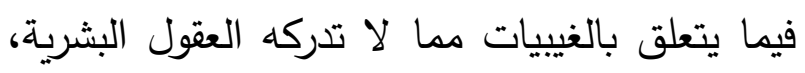

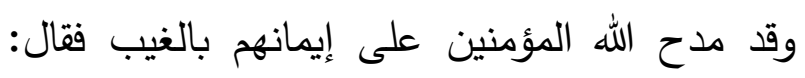
(الم" ذلك الكتاب لا ريب فيه هدى للمتقين الذين يؤمنون بالغيب ) [البقرة: ( 1 -ب]. وأقول أيضًا: إنَّه لا تعارض بلين البرة: بين آيات القرآن وأحاديث

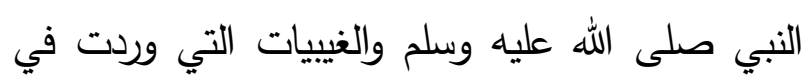
السمعيَّات، لا تعارض بينها وبين التقكير السليم أو وليه ولئي

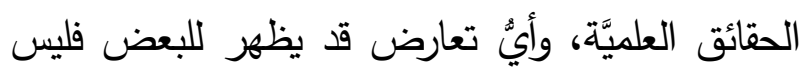
منشؤه الخبر الذي أتى عن الله تعالى ورسوله صلى تعلى الله

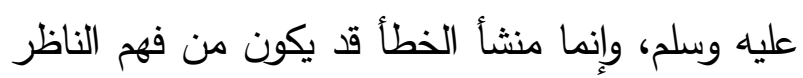
نفسه، أو خطأ في التطبيق والتتسير، أو حتى خطأ في هذه النظريات والقوانين. وقد تعرضت في هذا البحث لمناقشة النظرية

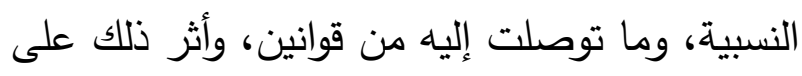
جملة من مسائل العقيدة.

\section{المقدمة}

الحمد الله ربّ العالمين، والصَّلاة والسََّلام على أشرف المرسلين، سيدنا محمد وعلى آله وصحبه أجمعين، وبعد: فإن النظرية النسبية من أهم النظريات التي ظهرت في القرن العشرين، والتي قدَّم بها أينشتاين مفهومًا جديدًا للفيزياء، وقدَّمت تصورات جديدة عن مجموعة من الأشياء مثل الجاذبيَّة والزمان والسرعة والكتلة والطاقة، خالف بها أينشتاين ما توصل إليه جماعة من الباحثين قبله مثل نيوتن. لذلك كان من الجدير بهذه النظرية أن تلقى اهتمام

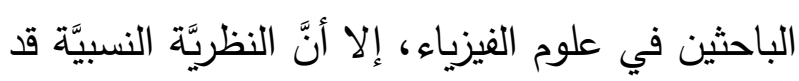

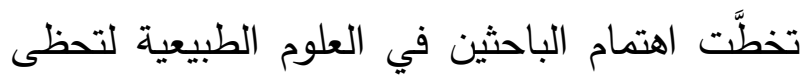
باهتمام كبير عند طبقة عريضة من الناس، حتى الباحثين في العقائد والأديان من أصحاب الديانات،

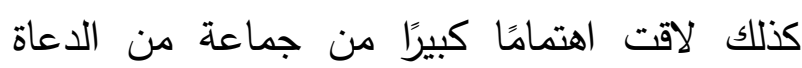
الإسلاميين وخاصَّة الباحثين في مجال الإعجاز العلمي في القرآن والسنَّة؛ فنجد جماعة من الدارسين يحاولون تقديم تفسيرات لآيات قرآنية وأحاديث نبوية، أو أمور من الغيبيات من خلال النظرية النسبية. وهذا أمر من الخطورة بمكانٍ؛ فإن الإسلام يؤمن من فئن

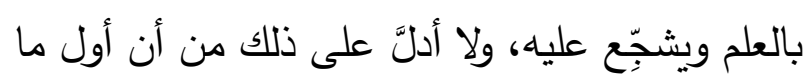

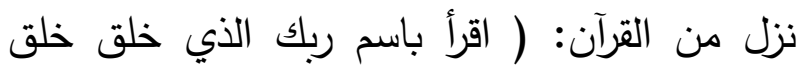

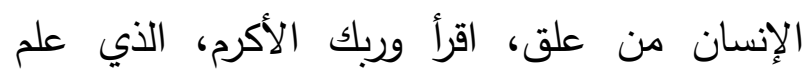

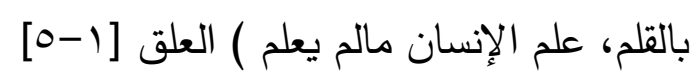


بصفة خاصة، وكيفية تناولها من قبل البعض بصورة

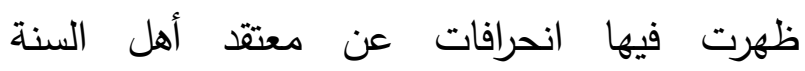

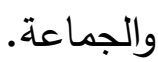

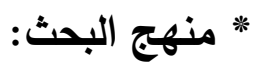

تتبع الدراسة منهجين أساسين لمعالجة الموضوع

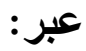
1- المنهج الاستقرائي: وذلك باستقراء قوانين النظرية النسبية محل البحث من مواضعها. r- المنهج التحليلي: وذلك من خلال مناقشة قضايا موانها.

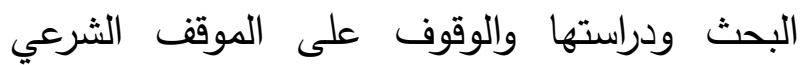
منها.

* يثتمل البحث على مقدمة وثلاثة مباحث وخاتمة، على النحو الآتي:

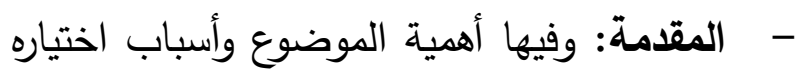
ومنهج البحث فيله. - المبحث الأول التعريف بأينشتاين ونظريته

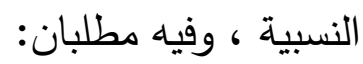
( ) المطلب الأول: ألبرت أينشتاين حياته ونظريته

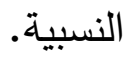

r ) المطلب الثاني: محاور النظرية النسبية. المبحث الثاني: موقف بعض المفكرين والعلماء المسلمين من النظرية النسبية وتحته مطلبان: المطلب الأول: أقوال بعض الفظرية المفكرين والعلماء في

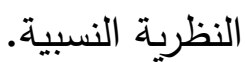
المطلب الثاني: استدلالات بعض العلماء المفكرين بالنظرية النسبية على بعض الآيات والأحاديث

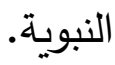

* أهمية الموضوع وأسباب اختياره: وكان اختياري لذلك الموضوع لعدة أسباب منها: 1- الاهتمام البالغ بهذه النظرية خاصة من الباحثين في الإعجاز العلمي في القرآن والسنَّة. r- ما ترتَّب على ربط تلك النظرية بأمور العقيدة من خلط وخطأ. * أهداف البحث: تهدف الباحثة من خلا البحث إلى عدة أمور أهمهما: 1- بيان موقف أهل السنة من ربط النظرية النسبية

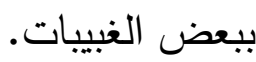
r- بيان موقف أهل السنة من ربط النظرية النسبية بالإعجاز العلمي في القرآن الكريم.

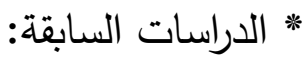
من الدراسات التي تناولت الموقف الثرعي من

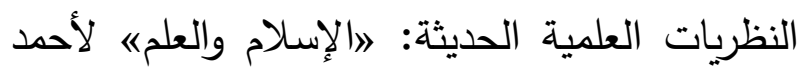
غراب، و 》الإسلام والعلم الحديثش لعبد الرزاق نوفل، و 》الدين والعلم الحديثه، و 》الإسلام بين العلم والدينه الشوقي أبو خليل، و 》الإسلام والعلم التجريبي" ليسوف السويدي، و النظريات العلمية الحديثة مسرتها الفكرية وأسلوب الفكر التغريبي في ولني التعامل معها دراسة نقديةه للدكتور حسين بن محمد حسن الأسمري. وقد تتاولت هذه الدراسات الكلام على موقف الإسلام من العلم الحديث والنظريات العلمية بشكل عام، وقد تميزت دراستي بتسليط الضوء على النظرية النسبية 
• ب9 ام، نشر دراسته عن: النسبية العامة والنسبية

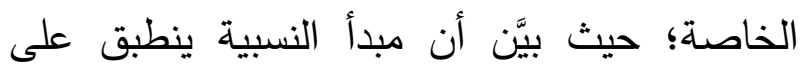

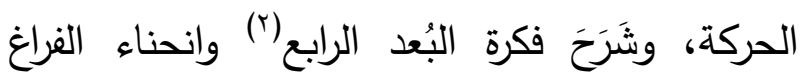
(المكان) (الم) (")

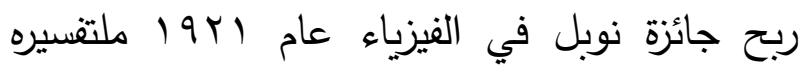
للتأثير الكهرضوئي( ). وأينشتاين مكتشف نظرية النسبية، الخاصة والعامة .... وكان من أهم نتائج النسبية الخاصة مفهوم تَداخُل الزمان والمكان وتَرَادُف الطاقة والكتلة. وقد تبع ذلك بالنظرية النسبية العامَّة التي تُعتبرَ تعميمًا

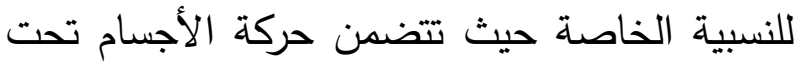
تأثير الجاذبية. وبالإضافة إلى نظرية النسبية. وفي عام سبوام هاجر أينشتاين إلى الولايات

() البعد الرابع هو البعد الذي أضافه أينتتين من خلال النظرية النسبية

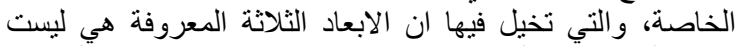

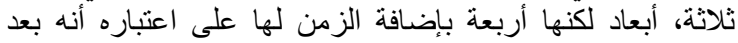

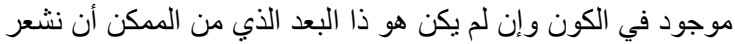
بها، و وعليه قامت النظرية النسبية. https://ar.wikibooks.org/wiki/\%D8\%A7\%D9\%84\%D8\%A8\% D8\%B9\%D8\%AF_\%D8\%A7\%D9\%84\%D8\%B1\%D8\% A7\%D8\%A8\%D8\%B9

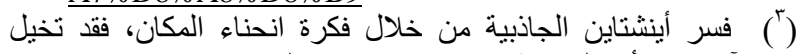

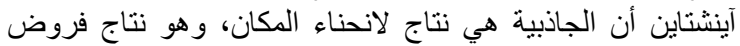

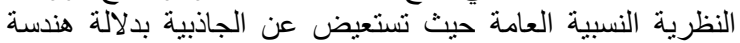

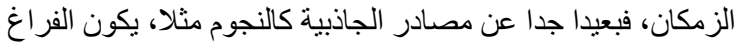

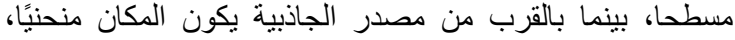

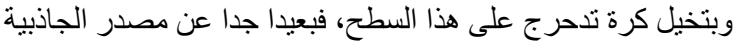

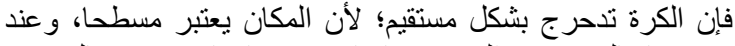

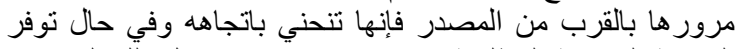

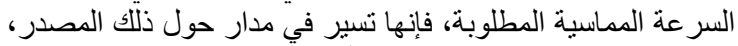

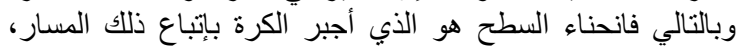

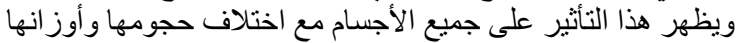

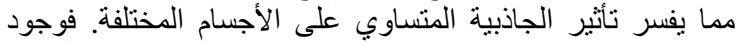

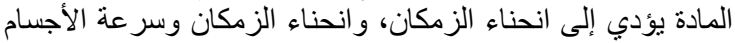

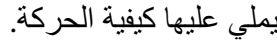
http://kenanaonline.com/users/tetraneutron/posts/285851

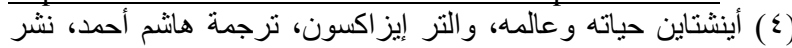

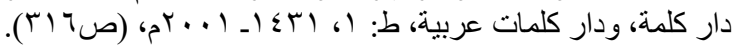

المبحث الثالث: نقد ما ذهب إليه بعض العلماء والمفكرين من ربط النظرية النسبية بأمور الغيبيات

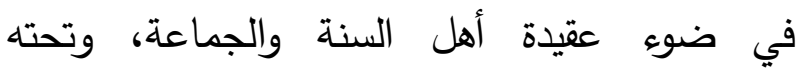

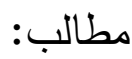
() المطلب الأول: قاعدة السلف في التعامل مع

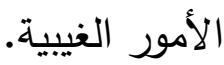
r) المطلب الثاني: الرد على دعاوى الرئه العلماء في الربط بين النظرية النسبية والأمور الغيبية. r) المطلب الثالث: الرد على دعاوى العلماء في لرئه الربط بين النظرية النسبية ووقوع المعجزات الأنبياء. ثم الخاتمة وفيها أهم النتائج والتوصيات..

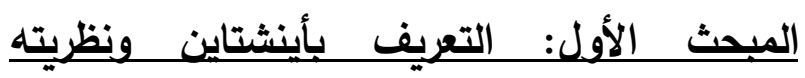
النسبية، وتحته مطلبان : الاول: المطلب الأول: ألبرت أينشتاين حياته ونظريته النسبية. ألبرت أينشتاين عالم طبيعة يهودي ألماني، وُلد في ألمانيا في مدينة أولم، سنة AV9 ام، ونشأ وتَعلَّم

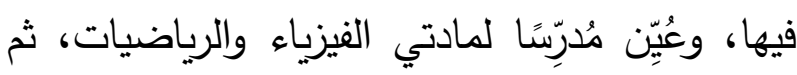
ترك أينشتاين التدريس وعمل بعد تَخرُُجه في مكتباء براءات الاختراع بمدينة برن في سويسرا، وأصبح

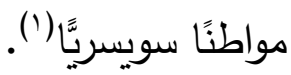
وفي عام 9 ام، نشر دراساتٍ عن: النظرية

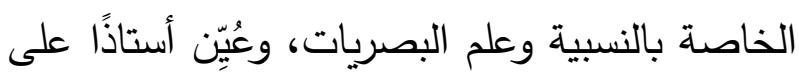

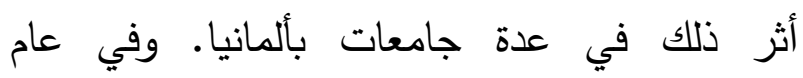

(1) صاحب النظرية النسبية أينشتني، عاطف محمد، دار لطائف، ط: 1) ،

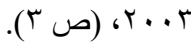




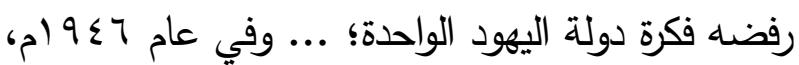

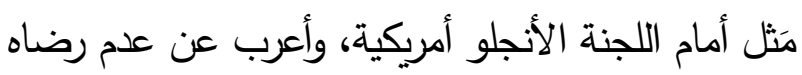

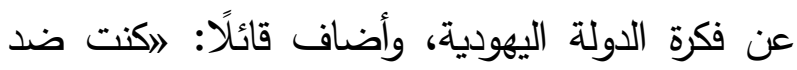
هذه الفكرة دائمًا (V)

وقد كانت النظرة الغربيَّة للعلم بعد الثورة على الحكم

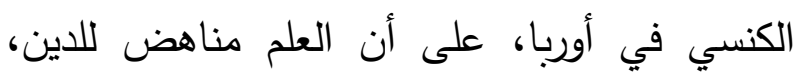
معادٍ له، فبات تعامل الغربيين مع العلم بنظرة علمانية، لا دينية، هي إلى الإحلاد أقرب(^).

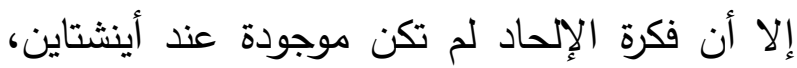
فهو يعد من العلماء المتديّنين، ولم يكن مقياس

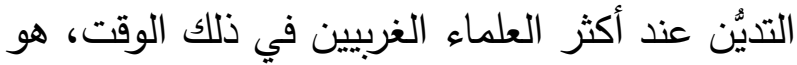

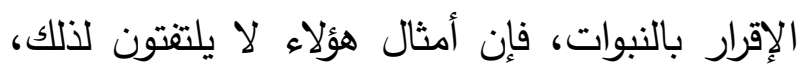

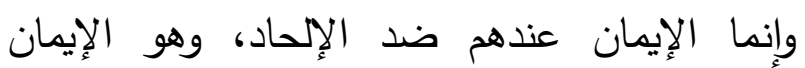
بوجود الله سبحانه فقط. فيجب أن تكون النظرة إلى موقف أينشتاين الديني إنما هو بالنظر إليه في دائرة الفكر الغربي، وبحسب الأجواء السائدة هناك لا بمنظارنا نحن؛ لأن رؤيته الدينية رؤية مختلفة عمَّا يعتقده أهل الكتاب أو أهل لأل الإسلام ممن يقرُون بالنبوات، ولكن هذه الرؤية الثبيهة برؤية أهل وحدة الوجود كانت في القرن بلني الثالث عشر غير مقبولة في التيارات البارزة؛ لأنها

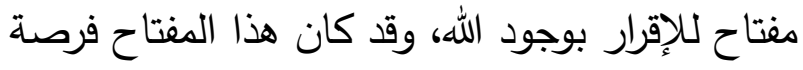

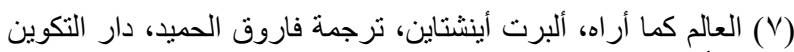

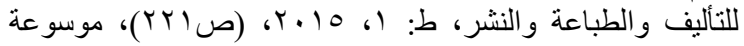

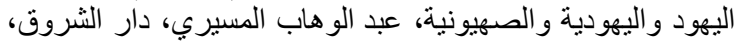

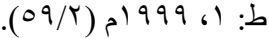

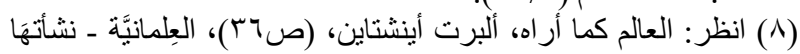

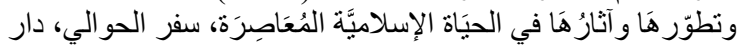

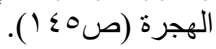

المتحدة، وأصبح أينشتاين مواطنًا أمريكيًا، واستمر في بحوثه العلمية(0). وقد لعب أينشتاين دورًا مهمَّا في تطوير القنبلة الذرية أثناء الحرب، ولكنه عارض استخدامها، بل وطالب بتحريم القنابل الذرية والكيدروجينية. وقد استمر أينشتاين في أبحاثه العلمية حتى وفاته في 11 إبريل سنة 1900 في برينستون، نيوجيرسي، وقد احتُّظ بدماغه في مركز جامعة برينستون الطبي. وعاش أينشتاين كيهودي في فترة من أهم وأصعب فترات اليهود في أوربا، وبخاصة في بلده ألمانيا، بين بدايات الحرب العالمية الأولى وغداة انتهاء الثانية، وعداء النازية لليهودية، حتى جاءته هو شخصيًّا تهديدات بالقتل اضطرته للهجرة إلى أمريكا، وقد زاد ذلك من انتمائه لليهودية، فقد كان يؤمن بفكرة الشعب العضوي، وبأن السمات القومية سمات بيولوجية ثُوَرث، وليست سمات ثقافية مكتسبة. وقد

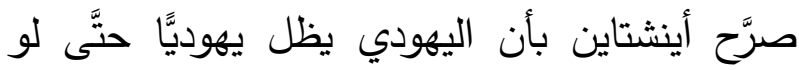

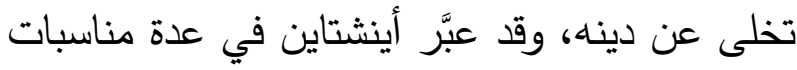

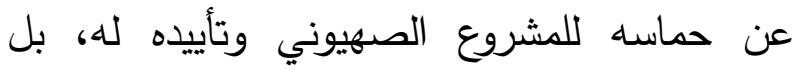
واشترك في عدة نشاطات صهيونية، ... حتى رأى قومه أن يعرضوا عليه رئاسة دولتها بعد وفاة حاييم

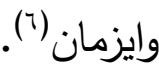
ثم إنه عاد بعد ذلك وعارض الفكر الصهيوني وأعلن

(0) انظر : صاحب النظرية النسبية أينشتين (ص V).

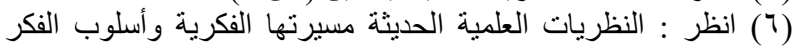

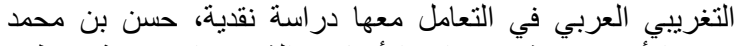

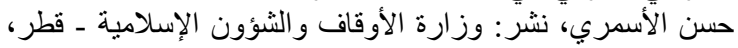

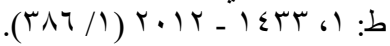


الإضافية للعجلة والجاذبية. والنسبية الخاصة - كما

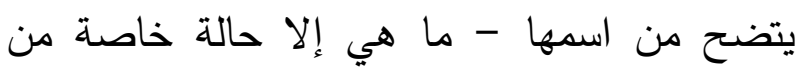
النسبية العامة الأعم والأشمل(r'). * النظرية النسبية الخاصة: وضعها أينشتاين سنة 9 ا9 ام، وهي تدرُس حركة

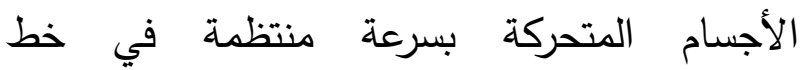

$$
\text { مستقيم (rir). }
$$

\section{وق بنيت النظرية على فرضين هما:} 1- سرعة الضوء في الفراغ لها نفس القيمة في

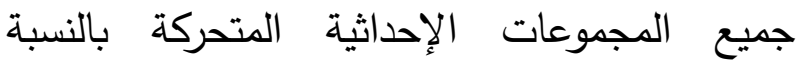
لبعضها بسرعة منتظمة (إطارات مرجعية لبعضها

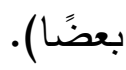

r- القوانين الطبيعية واحدة في جميع المجموعات

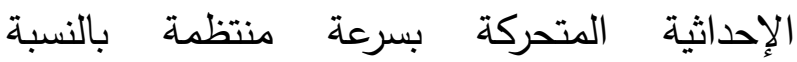

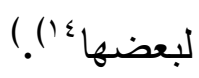

وقد نتج عن هذين المبدأين قوانين متعددة منها : ا- اختلاف طبائع الموجودات ومنها انكماش ملن ملين

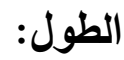
الأجسام تتصف بصفات مثل الطول والحجم والحرارة أو البرودة، وقد نظرت النسبية إلى طبائع الأشياء على أنها نسبية تتغير بتغير الحركة والسرعة.

( T M الزمان و المكان اليوم، مجموعة من المفكرين، ترجمة محمد وائل

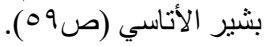

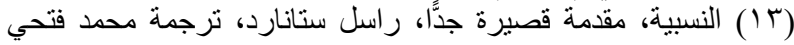

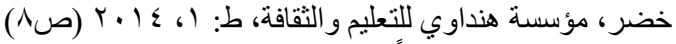

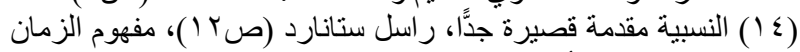

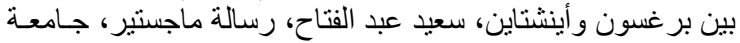

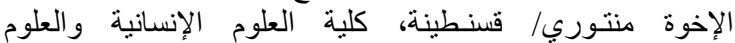

الاجتماعية، قسم الفلسفة، (صنم/ (1) ).
للمتدينين الغربيين باستثماره في إثبات أصولهم الدينية وفي مقدمتها الإقرار بوجود الرب سبحانه

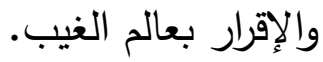
ورغم أن موقف أينشتاين من التدين لم يكن واضحًا إلَّا أن أغلب أجوبته تدل على أنى أنه يرى استحالة

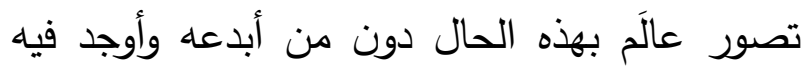

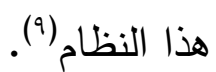
وأما إسهامات أينشتاين في علم الطبيعة فلا يمكن تقسيرها إلا باعتباره جزءًا من المنظومة العلمية

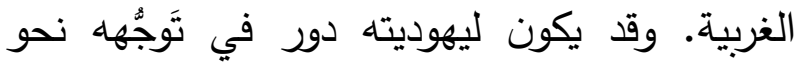
النسبيَّة، ولكن المنظومة العلمية الغربية ككل تظل العنصر المحدد النهائي (·). المطلب الثاني : محاور النظربية النسبية النظرية النسبية: نظرية فيزيائَّة (طبيعية) تبحث في عدة مواضيع التي تبحثها الفيزياء العادية، كالزمان والمكان والسرعة والكتلة والجاذبية والتسارع، ولكنها تتظر إلى هذه الأمور بوجهة نَظَرِ أُخرى (')".

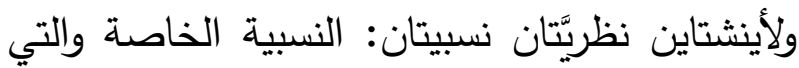
وضعها أينشتاين سنة هـ 9 (م، والنسبية العامة التي ولي ظهرت سنة 1917 19، وتركز النسبية الخاصة على تأثيرات الحركة المنتظمة على كلٍٍ من المكان والزمان. أما النسبية العامة فتتضمَّن التأثيرات

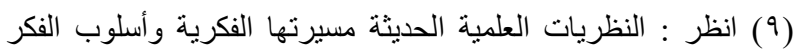

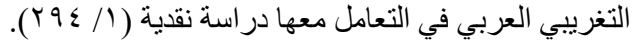

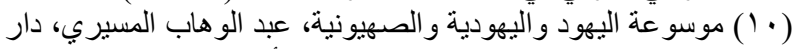

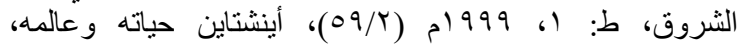

(11) الكون الأحدب، قصة النظرية النسبية، عبد الرحيم بدر (صب ا) 
الكتلة(19)، وكل زيادة في الكتلة تتبعها زيادة في الطاقة يعبر عنها بضرب الكتلة في مربع سرعة

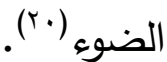
ولذا فتعد النظرية النسبية في ربطها بين الكتلة والطاقة الذي اكتشفه أينشتاين هي بداية نزع المادية

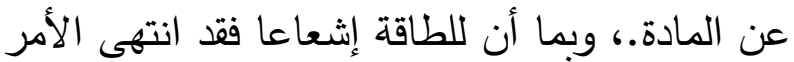
عند ذلك بالمادة إلى أن أصبحت إشعاعا متحركاً ،ولم يعد بالإمكان إحكام قياس هذا الإشعاع بمقاييس الزمان المعروفة من قبل ، وهكذا ظهرت أفكار جديدة مستمدة من نسبية أينشاتين، ما دامت المادة كلها إشعاعًا في حالات مختلفة متجِيّدة مرة ومنطلقة في هيئة ضوء أو مغناطيسية أو حرارة أو هالو كهرباء... إلخ، فليس في الكون كله شيء غير

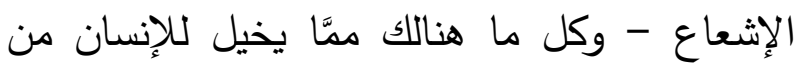
التغاير - هو تغاير إشعاع متجسد من إثعاع

منطلق (r) (r)

\section{النظرية النسبية العامة:}

ظهرت النظرية النسبية العامة سنة 1919 م، وهي تدرس حركة الأجسام المتحركة بتسارع(rr)، وقد بُنِيَتْ على مبدأين أساسيين؛ هما: 1- مبدأ التكافؤ: وينصُّ على عمومية السقوط الحُرِّ، بمعنى أن جميع الأجسام تسقط بنفس المعدل في مجال الجاذبية، بغض النظر عن كتلها وتركيبتها

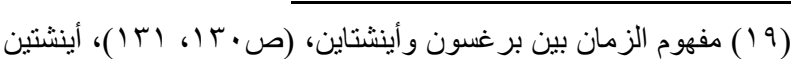

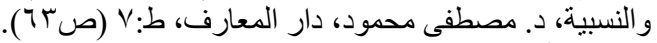

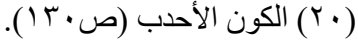
(Y) (Y) الكو فلسفة العلوم، النظريات الذرية و الكو انتم و النسبية، د عبد النتاح

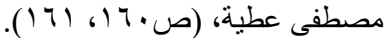
(rr) النسبية، مقدمة قصيرة جدًا، راسل ستانارد (صد).
وقد كان الاعتقاد السائد أن الكتلة أمر ثابت لا يتأتَّرّ بحركة الجسم أو سكونه، إلا أن النظرية النسبية جاءت لتقول خلاف ذلك، فالكتلة نسبية أيضًا مثلها مثل الزمان والمكان، فإنها مقدار متغير، فكلنا

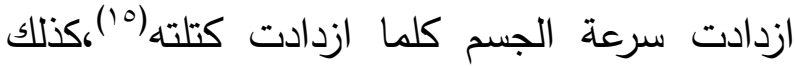
خرجت النظرية النسبية بقانون انكماش الطول('1"). r- زيادة الكتلة بزيادة السرعة: فتقول النظرية النسبية: إن الكتلة تتغيَّر بالحركة، وتزداد كلما ازدادت السرعة، وهذا خلاف ما تقوله الفيزياء الكلاسيكية من أن الكتلة ثابتة لا تتغير،

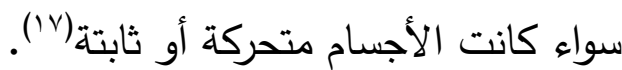
ب- ق قانون الطاقة والكتلة: المادة في الفيزياء الكلاسيكية هي ما له كتلة وحجم ويشغل حيزًا من الفراغ(^)، فجاءت النظرية النسبية وربطت بين الكتلة والطاقة عن طريق قانون تكافؤ الكتلة والطاقة، وكانت الفيزياء الكلاسيكية قد ربطت

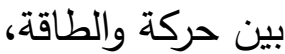
فالجديد الذي قدمه أينشتاين، هو أن المادة في حد ذاتها عبارة عن مخزن للطاقة، وأن كمية المادة في الكون ليست ثابتة، وكذلك كمية الطاقة، وإنما الثابت هو مجموع المادة مع الطاقة، فالمادة طاقة متحجرة، والطاقة هي مادة متبخرة، وتغير الطاقة يرتبط بتغير

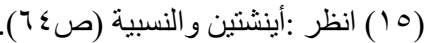

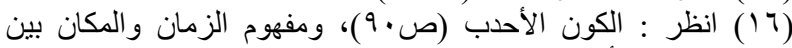
بر غسون و أينشتاين (ص الأس 9 (1) (1) ).

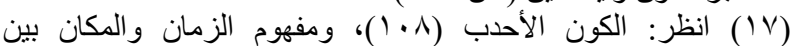

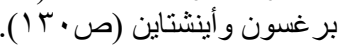

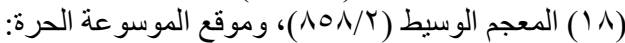

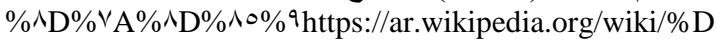

${ }^{9} \mathrm{~A} \% \wedge \mathrm{AF} \% \mathrm{D}$ 


\section{الحوادث في النظرية النسيية :}

الكون في النظرية النسبية مؤلَّف من حوادث؛ كل نقطة فيه حادث من الحوادث لها مكان وزمان، يحدد

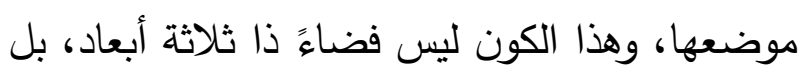
هو أكبر من ذلك - فالفضاء ذو الأبعاد الثلاثة شيء متصور وجوده في لحظة معينة فهو لا يشمل

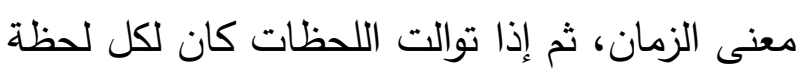
فضاء ذو ثلاثة أبعاد خاص بها - فإذا تصورات تصونا هذه الفضاءات مرتبة الواحد منها تلو الآخر في ترتيب زمني متصل؛ وصلنا إلى معنى المكان الزمان،

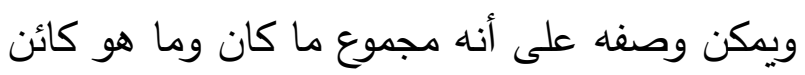

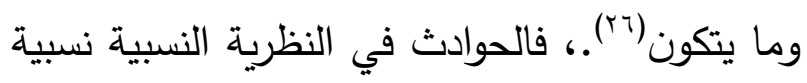

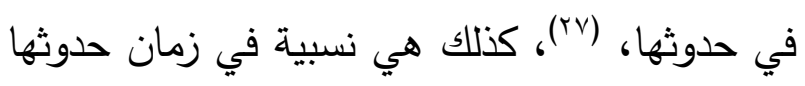

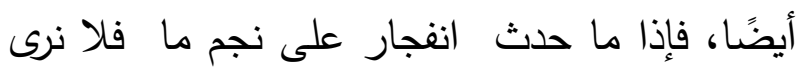
نحن ذلك الانفجار على الأرض إلا بعد أربع سنوات فات لهات من وقوعه مثلا (r^)

\section{الزمان في النظرية النسبية :}

ويعرف الشريف الجرجاني الزمان بأنه: "هو مقدار حركة الفلك الأطلس عند الحكماء، وعند المتكلمين: عبارة عن متجدِّد يقدر به متجدد آخر موهوم، كما الاطي

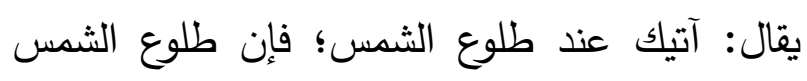
معلوم ومجيئه موهوم، فإذا قرن ذلك الموهوم بذلك فلك لتئ

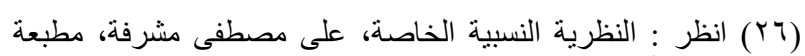

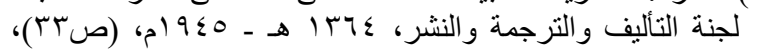

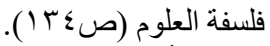

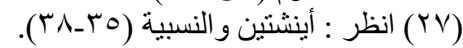

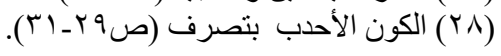

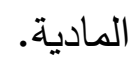

ولقد لوحظ أن الجاذبية تتسبب في تسارع الأجسام المتساقطة، ولكن لوحظ أيضًا من تطبيقات النظرية

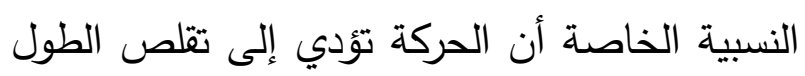
وتمدُّد الزمن. ولذلك فقد حاول أينشتاين أن يبرهن أن أن أندان الجاذبية أيضًا يجب أن تؤثر على الزََّّكَان (rr)

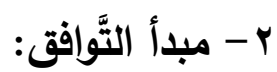

في النظرية النسبية العامَّة يجب أن توضع هذه القوانين بصورة عامة ومستقلة عن اختيارنا لأي لئي إحداثيات خاصَّة، زمنية أو مكانية. وبلفظ آخر: فإن القوانين الفيزيائية يجب أن تتوافق؛

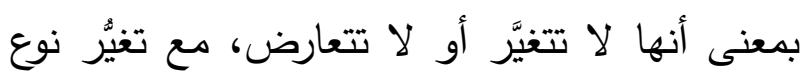

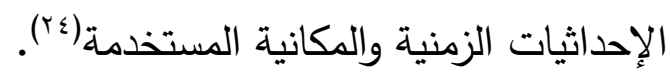
ويرى أينشتاين من خلا نظريته أن المقاييس في

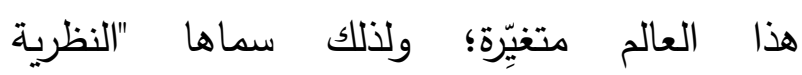
النسبية"؛(ro). فإن أينشتاين ينفي وجود شيء ثابت هذاب في هذا الكون (عدا شيء واحد، وهو سرعة الضوء).

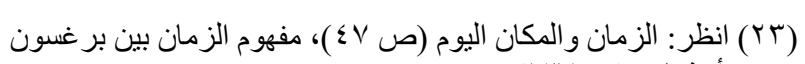

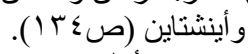
كما هو مبدأ التكافؤ؟ وكيف يقود الى النسبية العامة؟.. بقلم: معز جعفر http://www.sudanile.com/ / Ir 1 \%०

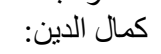
مبدأ التكافؤ في النظرية النسبية العامة، أمجد خرواط:

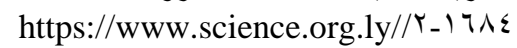

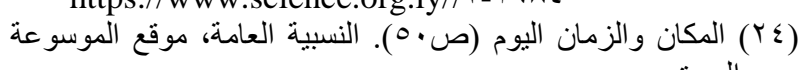

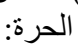
https://ar.wikipedia.org/wiki/\%D\%^A\% $\% \mathrm{D}^{\vee} \%$ ^ \% ${ }^{9}$ $\mathrm{D} \% \wedge \uparrow \%{ }^{\natural} \mathrm{D} \% \wedge \mathrm{B} \%\left\ulcorner\mathrm{D} \% \wedge \mathrm{A} \%{ }^{\wedge} \mathrm{D}^{\wedge} \%{ }^{\natural} \mathrm{A} \% \mathrm{D} \%{ }^{\wedge} \mathrm{A}^{\natural}\right.$ $\% \mathrm{D} \% \wedge \mathrm{A} \%{ }^{\vee} \mathrm{D} \% \wedge \leqslant \% \%{ }^{9} \mathrm{D} \% \wedge \mathrm{B} \%{ }^{9} \mathrm{D} \% \wedge \mathrm{A} \%{ }^{\vee} \mathrm{D}$ $\% \wedge 0 \%{ }^{\wedge} \mathrm{D}^{\circ \wedge} \mathrm{A}^{9}$

$$
\text { (YO) الكون الأحدب (ص9 1)، (Y). }
$$




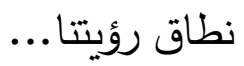

ففكرة التزامن التي افترضتها الفيزياء الكلاسيكية كفكرة مطلقة، خرج أينشتاين من خلال النظريـة النسبية أنها نسبية أيضًا وليست مطلقة، وهكذا، فإن الحدث المعين قد وقع في أوقات مختلفة بالنسبة لأماكن مختلفة (rr).

\section{المكان في النظرية النسبية :}

المكان في اللغة هو الموضع الحاوي للشيء(r؟".

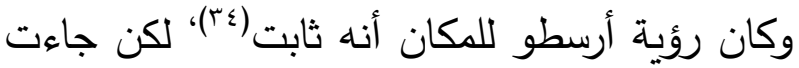
الفيزياء الحديثة لتقول غير ذذلك؛ فالمكان عند الفيزيائيين نسبي لا واقعي، فقال نيوتن بتحركه، ثم جاء أينشتاين ليقول بسبيته، وأنه غير ثابت لإمكان تأثره بالجاذبية، ولتغير طوله عن طريق تغير سرعة

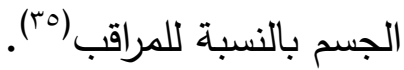
أن ثابت المكان في النظرية نسبيُّ، فليس في الكون مكان مطلق، فقياس الحركة على الأرض لا يظهر

$$
\text { إلا بالقياس إلى شيء ثابت، ... }
$$

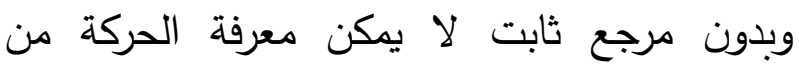
السكون، وعلى الأكثر يمكن معرفة الحركة النسبية

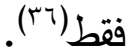

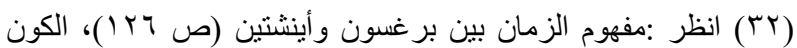

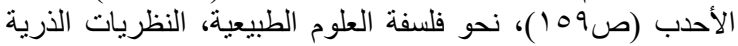

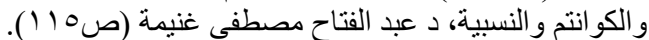

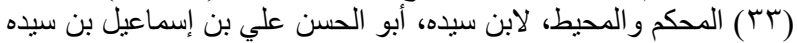

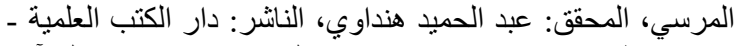

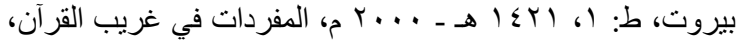

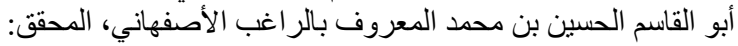

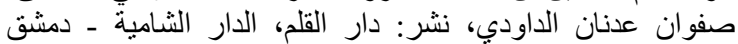

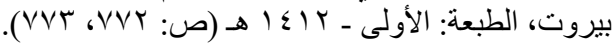

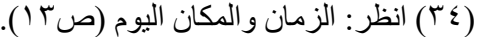

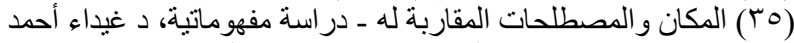

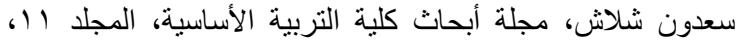

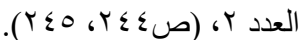

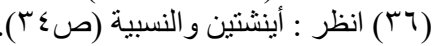

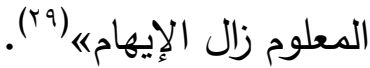
أما التعريف العلمي عند الفزيائيين والفلكيين، فإن أرسطو يعرّف الزمن بأنه "عدد الحركة حسب السابق واللاحق"؛ أي أنَّ الزمن يمكن تقسيمه إلى آنات متعاقبة ومتتالية، فالآن بالنسبة للزمن كالنقطة بالنسبة للخط المستقيم، (·r). وقد أدخل أينشتاين من خلال النظرية النسبية ثبات سرعة الضوء، فلا يوجد شيء في الكون يمكن أن تصل سرعته لأكبر من سرعة الضوء ('rا". كما أدخل أينشتاين الزمن كبعد رابع للأبعاد المكانية الثلاثة: الطول والعرض والارتفاع، وافترض أيضًا أن الزمان نسبي كالمكان،

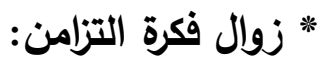

إن كلمة 》الآنه في قانون الكون لا حقيقة لها، فالقول بأنَّهَ من الممكن أن يحدث على الأرض وعلى الشعرى اليمانية أحداث متواقتة في آنٍ واحد، فهو أمر مستحيل؛ لأنها أنظمة مختلفة لا اتصال بينها، والاتصال الوحيد وهو الضوء يأخذ آلاف السنين لينتقل من واحد من هذه الأنظمة إلى الآخر، ونحن حينما نرى أحد هذه النجوم ويخيل إلينا أننا نراه، الآن، نحن في الحقيقة نراه عن طريق الضوء الذي ارتحل عنه منذ ألوف السنين ليصلنا، نحن في الواقع نرى ماضيه ويخيل إلينا أنه حاضره. وقد يكون في الحاضر قد انفجر واختفي أو ارتحل بعيدًا خارج

(Yq) (Yq) التعريفات، للجرجاني (صع (1) ). (1)

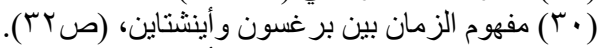

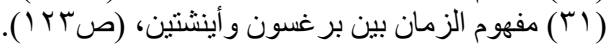


سرّ انزعاج التيار المادي في صورته الماركسية مثلًا من هذه النظرية(1). وقد كان رأي أينشتاين نفسه أن هذه النظرية "مسألة علمية محضة، وليس لها أدنى علاقة بالدين"، ويعد هذا الموقف صدمة أخرى للاتجاهات الوضعية والمادية التي غطت على غيرها في القرن التاسع عشر الميلادي (الثالث عشر الهجري)، فهم كانوا

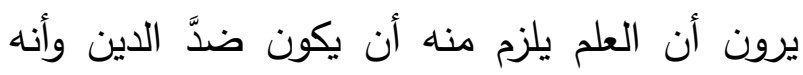
البديل عنه، أما هنا فنجد موقفًا آخر يجعل النظرية مندية مسألة علمية لا علاقة لها بالدين، وما كان هذا الموقف ليرضي الاتجاه الوضعي والمادي والأطراف

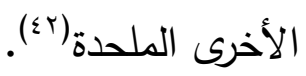

المبحث الثاني: موقف بعض المفكرين والعلماء المسلمين من نظرية النسبية ،وتحته مطلبان : المطلب الأول : أقوال بعض المفكرين والعلماء في

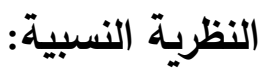
انبهر كثير من العلماء والمفكرين بهذه النظرية بعد

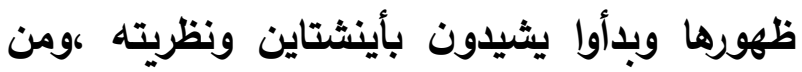
هؤلاء :

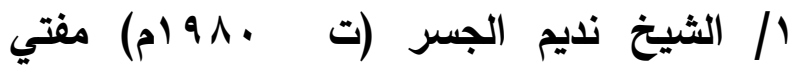
الثمال اللبناني يقول : " لا تصدق أن عظيما مثل أينثتاين يتناقض عقله فينكر البديهيات" إ"، بل استنكر أن توجد غرابة أو مصادمة بين نتائج

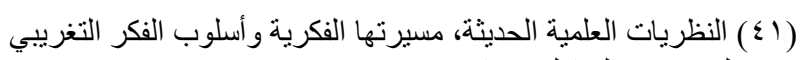

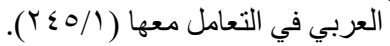

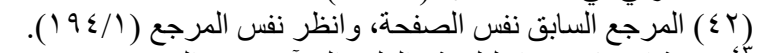

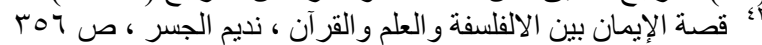

فإذا جئنا إلى الكون فنغس الأمر بالنسبة له أيضًا؛

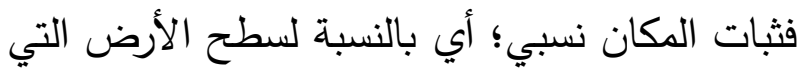

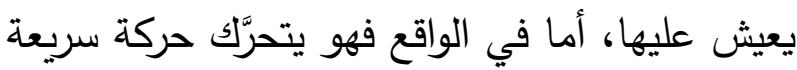

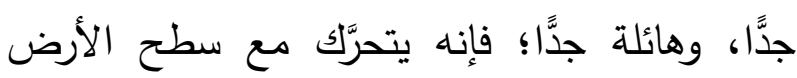
والأرض نفسها حركات متعددة جدًّا في آن واحد..

فلا سبيل إلى معرفة المكان المطلق لأي شيء في

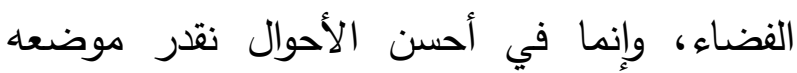

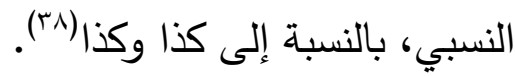
وكذلك بالنسبة للجهات، فإن الثمال والجنوب الثب والشرق والغرب وفوق وتحت ما هي إلا اصطلاحات تدل على جهات معينة في الكرة الأرضية فقط، فلا معنى لهذه الاصطلاحات عندما ننظر نظرة شاملة إلى الكون كله(ra).

\section{النظريـة النسيية ونظرية المصادفات : النون}

وقيل: المصادفة هي "خلو النظام الكوني من الإله"، وقد اعتمد على هذه النظرية فلاسفة الفلسفة المادية

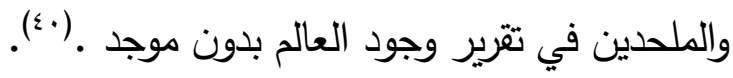
وقد جاءت النظرية النسبية لتثبت بطلان نظرية المصادفة؛ إذ أنها بيَّنت أن العالم محكوم بقوانين ونظام محكم لا يتخطاه، وكونه اعترف بذلك، يفسّر

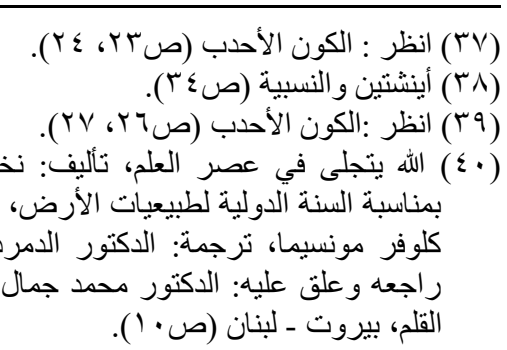


المطلب الثاني : استدلالات بعض العلماء المفكرين بالنظرية النسبية على بعض الآيات والأحاديث النبوية : بط:

ويعد هذا المطلب هو المشكلة الذي عقد هذا البحث

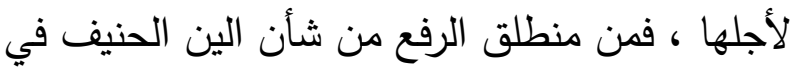

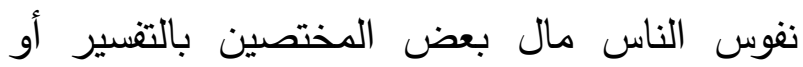
الإعجاز العلمي للربط بين العلم التجريبي والعلوم الغيبية ، ومن ذلك : / / ادعاء بعض العلماء وجود الإشارة للنظرية النسبية في مواضع من القرآن الكريم وهي : أرهي

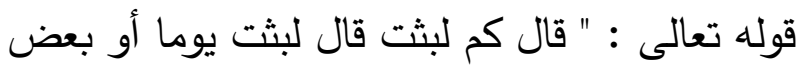

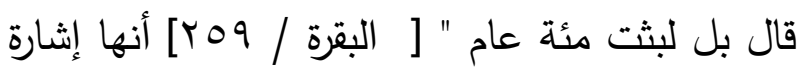

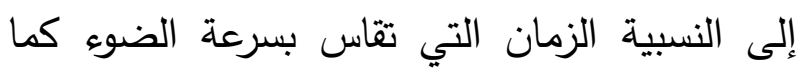

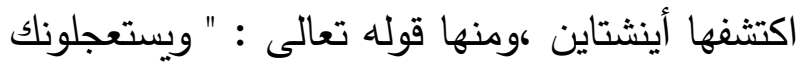
بالعذاب ولن يخلف الله وعده ، وإن يوما عند ربك

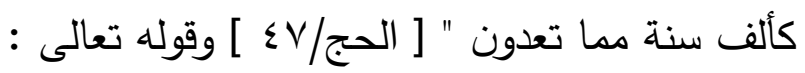
" يدبر الأمر من السماء إلى الأرض ثم يعرج إليه

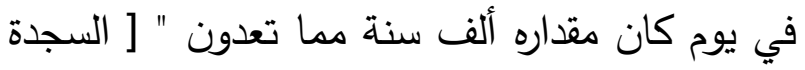

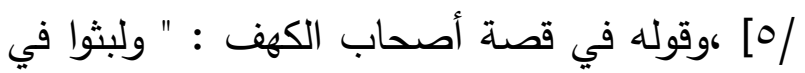
كهفهم ثلاثمئة سنين وازدادوا تسعا ، قل الله أعلم بما لبثوا "[ الكهف / هب-r-r]] ، وقوله : " قال كم لبثت

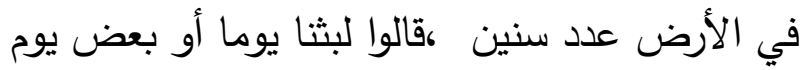

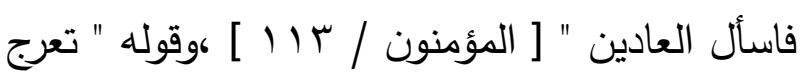

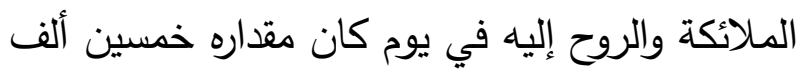

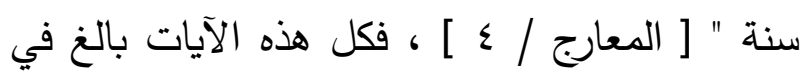

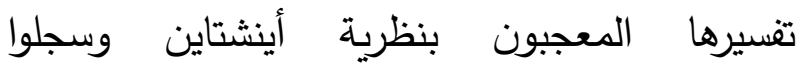

النظرية النسبية وبدائه العقول ... حتى أنه لا يرى تصادم هذه النظرية مع أي ضرورات في العلوم

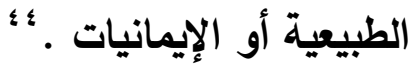
ومن استدلالاته الخاطئة : " الزمن ..أي عنصر الائيات السرعة هو الذي يتحكم في طول المادة وفي كتلتها

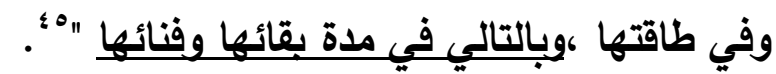

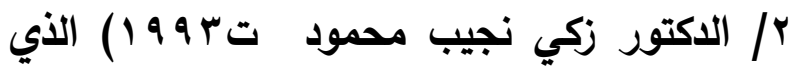
يرى من نظرية أينثتاين تغير صورة العالم من حتمية إلى نسبية احتمالية ، فتغيرت صورة العالم تبعا لذلك . ب؛ r/ وزاد الطين بلة الاكتور مصطفى محمود

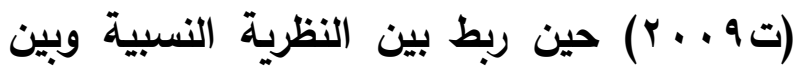
الأمور الأخروية بقوله : " سنتحول في الجنة إلى لى أجسام نورانية ،والأجسام النورانية لها سرعة الأهر تساوي سرعة الضوء ،ومن يتباطأ عندها الزمن

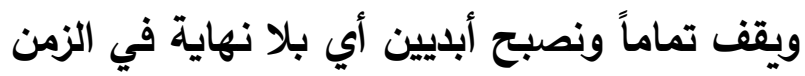

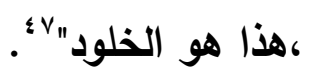

\& / ومن المادحين لهذه النظرية ، د. دمعد مرحبا

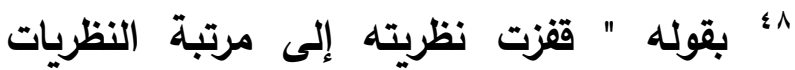
الخالدة وجعلت أينثتاين في طليعة العظماء الذين يثح بهم التاريخ "وغيرهم الكثير كما سيأتي . 
هي سرعة الضوء “ْ، بل ظن صغر الحجارة من

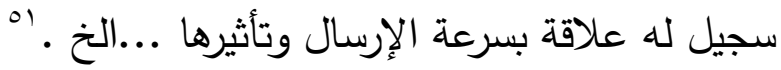

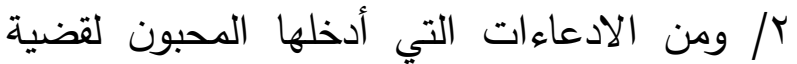

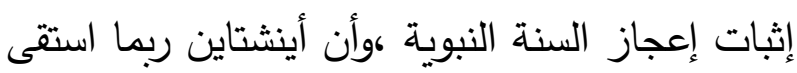

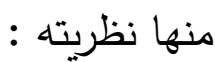

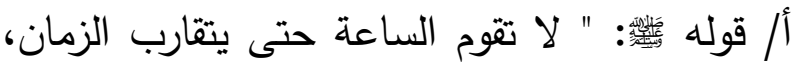
فتكون السنة كالشهر والثهر كالجمعة ،والجمعة كاليوم ،واليوم كالساعة " or . or

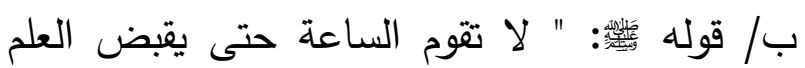
،وتكثر الزلازل، ويتقارب الزمان ..." rه.

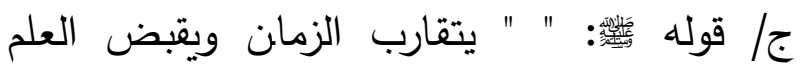
كويلقى الشح، وتظهر الفتن ، ويكثر الهرج ..." $.0 \leqslant$

بل قد رد عليهم من هو متخصص في الفيزياء وأثبت خطأ تفسيراتهم من عدة نواحي: / خلطهم بين نسبية المواقيت ونسبية الزمن في

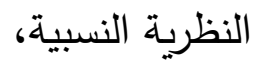
r/ ادعاؤهم تأييد القرآن للنظرية النسبية بلا تحقيق •

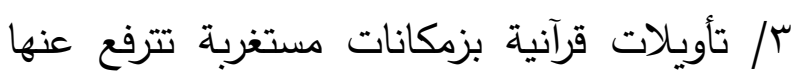
حتى النسبية .

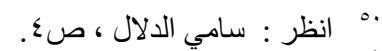

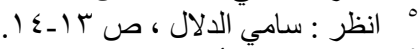

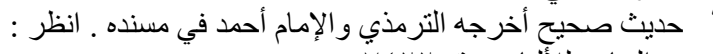

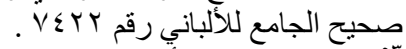

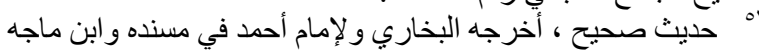

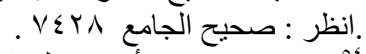

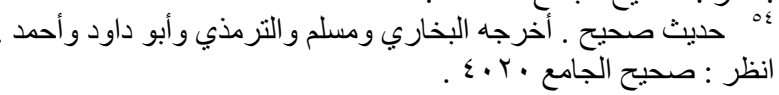

المعادلات الرياضية لإثبات صحة ماجاء في القرآن

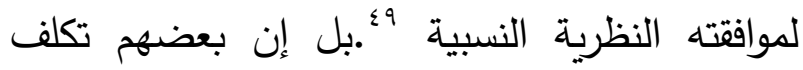

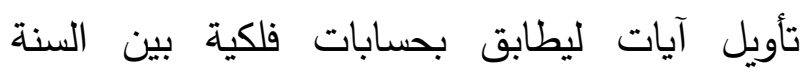
الضوئية في آيات أخرى منها تفسير قوله تعالى :" آنسات

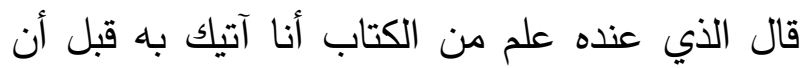

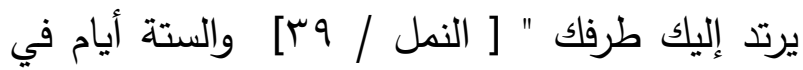
قوله تعالى : " ولقد خلقنا السموات والأرض في ستة

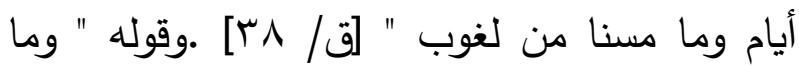

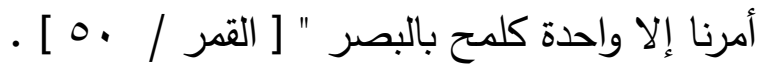
ووصل التكلف العلمي في تفسير الآيات بالنظرية النسبية عند البعض ما يمكن تسميته درجة الخيال

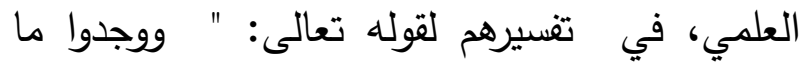

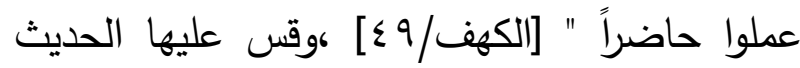
عن الجنة والنار إذا ورد في القرآن بصيغة الماضي أو المضارع ،في قوله تعالى :" وأزلفت الجنة

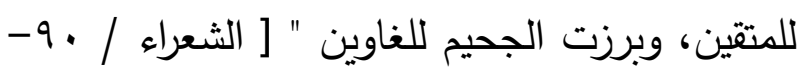
ب9]، بل زعم بعضهم قياسات سرعة الطير الأبابيل

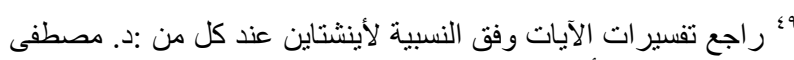

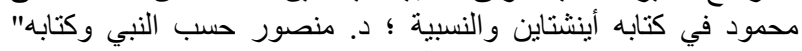

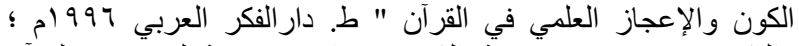

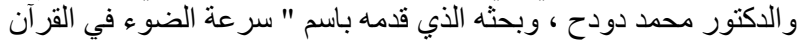

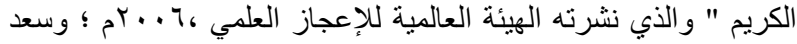

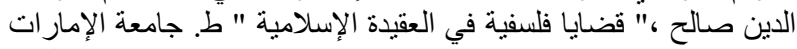

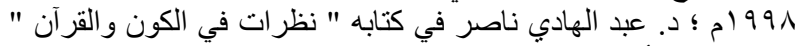

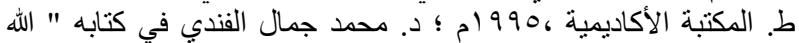

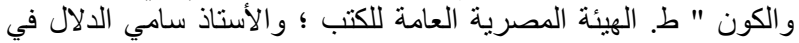

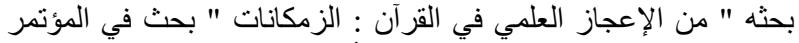

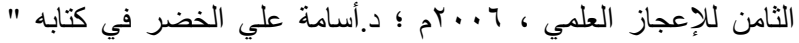

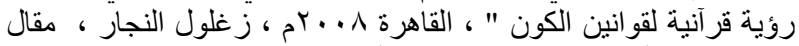

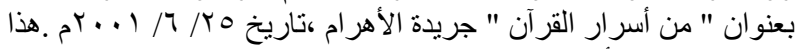

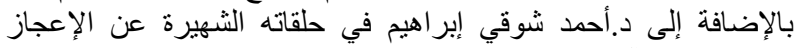
العلمي في القرآن و السنة في ثمانينات القرن العشرين ـ العئ 
من غير تكييف ولا تمثيل، ومن غير تحريف ولا تعطيل، وكنلك ينفون عنه ما نفاه عن نفسه - مع ما أثبته من تصني الصفات - من غير إلحاد، لا في أسمائه ولا في آياته، منه مانه

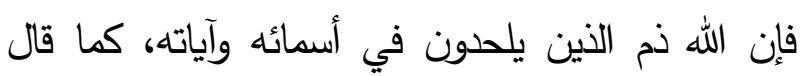
تعالى: (وذروا الخين يلحدون في أسمائه سيجزون ماكانوا

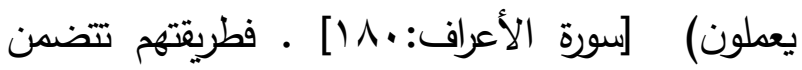

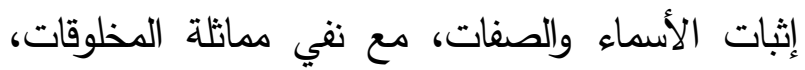
إثباتًا بلا تثبييه، وتتزيها بلا تعطيل، كما قال تعالى:

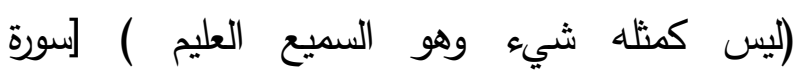
الثورى: (1]]، فقي قوله: (ليس كمثله شيء) رد للتشبيه والتثثيل، وقوله: ( وهو السميع العليم) رد للإحاد والتعطيله (ov).

وقال الشيخ ابن عثيمين رحمه الله: لاصفات الله عز وجل من الأمور الغيبية، والواجب على على الإنسان نحو

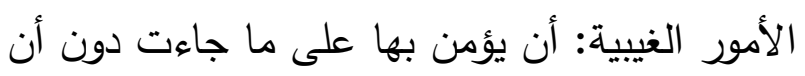
يرجع إلى شيء سوى النصوص قال الإمام أحمد:

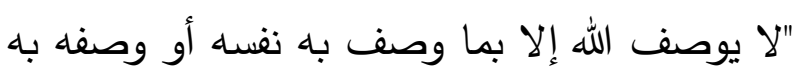

$$
\text { رسوله، لا يتجاوز القرآن والحديث". }
$$

يعني أننا لا نصف الله إلا بما وصف بله بانه نفسه في كتابه، أو على لسان رسوله صلى الله عليه وسلم.

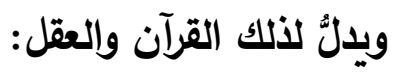
ففي القرآن: يقول الله عز وجل: ( قل إنما حرم ربي الفواحش ماظهر منها ومابطن والإثم والبغي بغير الفي الحق وأن تشركوا بالله مالم ينزل به سلطانا وأن تقولوا

و (ov)

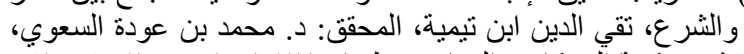

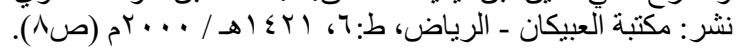

ع / ادعاءات نسبوية في السنة المشرفة وأن أينشتاين قد استقى منها نظريته .

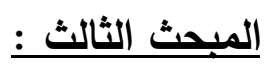

نقد ماذهب إليه بعض المفكرين والعلماء من ربط

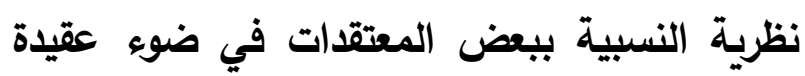
أهل السنة والجماعة ، وفيه ثلاثة مطالب: المطلب الأول:

قاعدة السلف في التعامل مع الأمور الغيبية : أهل السنة والجماعة يؤمنون بأركان الإيمان الستة الامور التيبه وهي الأمور الغيبية التي لا سبيل لمعرفة كنهها ولا كيفيتها ولا تعليلاتها إلا من طريق الوحي؛ الوالئ فالإيمان

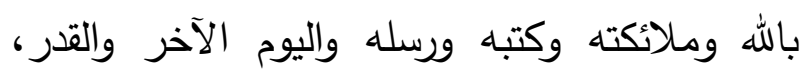
نؤمن بمعانيها التي جاء بها الوحي على وفق فهم وله ولهابه السلف الصالح ونترك الكيفية والتعليل حولها .. وطريق علم صفات الله تبارك وتعالى عند أهل السنة

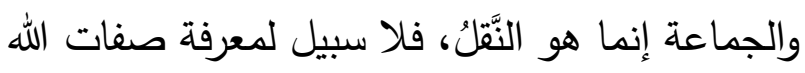

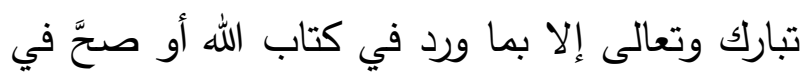
سُنَّة رسول الله صلى الله عليه وسلم.

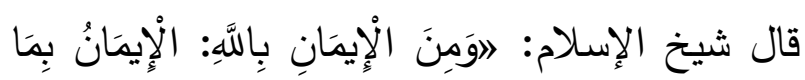

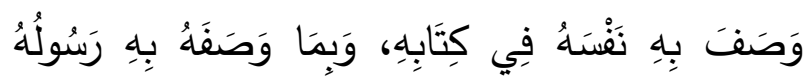

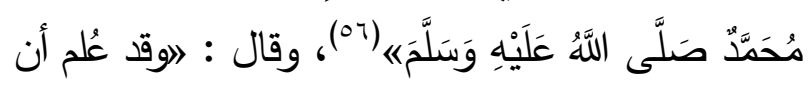

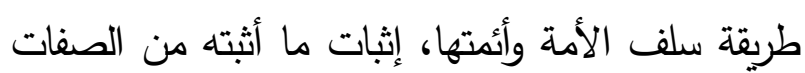

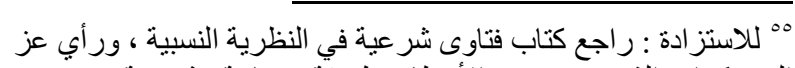
الدين كزابر الذي فند جميع الأخطاء بطريقة فيزيائية وشر عبية ، تحت

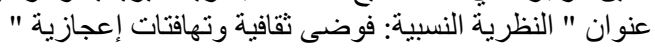
(07) العقيدة الوانطية: اعتقاد الفرقة الناجية المنصورة إلى قيام الساعة أهل

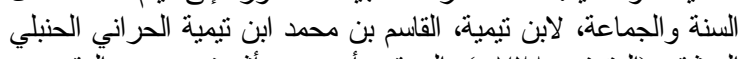

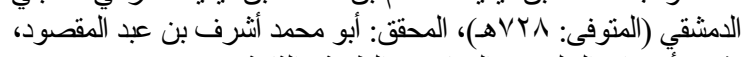

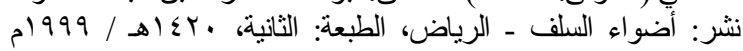

(ص) (OV) 
الكيفية لا تعلم ولا يجوز السؤال عنها لا يقال كيف

استوى 《) (7).

وقال العلامة ابن عثيمين رحمه الله: لافقال: ״والسؤال عنه بدعةه، فلا يجوز أبدًا أن نسأل عن أن صفة من صفات الله فنقول: كيف؟، ولا يجوز أيضا أن نقول: إذا صح هذا لزم منه هذا مما يمتتع على الله، يعني مثل الذين يقولون: إذا صح نزوله إلى السماء الدنيا لزم أن تكون السماء الثانية فوقه، فهذا حرام ولا يجوز، ولا يمكن أن يقدر هذا التقدير من عرف الله وقدره قدره، بل نحن موقفنا في هذه الأمور هو التسليم، وعدم التعرض لأي سؤال مثل هذه الأسئلة.

أما لو قال: ما معنى النزول؟ أو: ما معنى المجيء؟

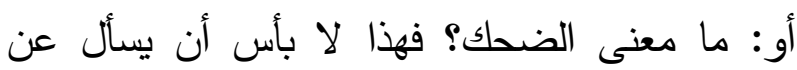
المعنى حتى يبين له معنى الاستواء مثلا، لكن كيف استوى؟ كيف ينزل؟ كيف يجيء؟ كيف عينه؟ كيف يده؟ كيف قدمه؟ فهذا لا يجوز . فالحاصل أن موقف أهل السنة والجماعة من الآيات والأحاديث الواردة في صفات الله عز وجل أن يمروها كما جاءت من غير تحريف ولا تعطيل ولا تكييف ولا تمثيله (')" فأهل السنة والجماعة في إيمانهم بأسماء الله تعالى وصفاته لا يتجاوزون النصوص الواردة في كتاب الله

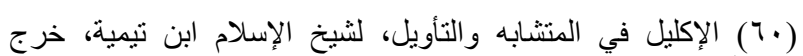

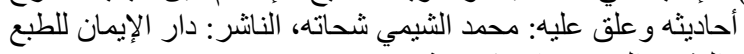

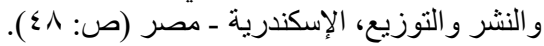

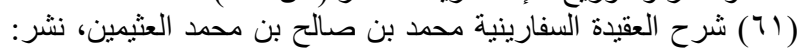

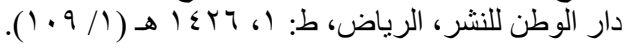

على الله مالم تعلمون ) [الأعراف، سب]، فإذا وصفت الله بصفة لم يصف الله بها نفسه، فقد قلت عليه ما لا تعلم وهذا محرم بنص القرآن. ويقول الله عز وجل: (ولا تقف ماليس للك به علم إن السمع والبصر والفؤاد كل أولئك كان عنه مسؤولاً)]الإسراء: بr]، ولو وصفنا الله بما لم يصف به نفسه، لكنا قفونا ما ليس لنا باه علم، فوقعنا فيما نهى الله عنهـ. وأما الدليل العقلي: فلأن صفات الله عز وجل من الأمور الغيبية ولا يمكن في الأمور الغيبية أن يدركها العقل، وحينئذ لا نصف الله بما لم يصف باه نفسه،

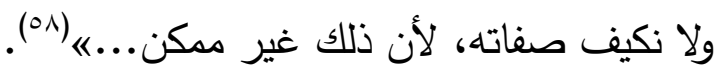
كما أن من الأمور المهمة في عقيدة أهل السنة والجماعة أنهم يؤمنون بمعاني أسماء الله تبارك وتعالى وصفاته، لكن يفوضون معرفة كيفيتها إلى الله تبارك وتعالى، على حد قول الإمام مالك رحمه الله

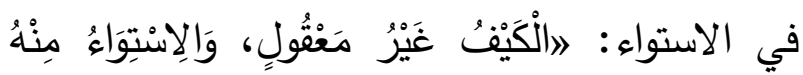

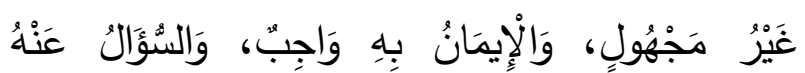

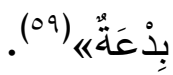
قال شيخ الإسلام: لاوقد تلقى الناس هذا الكلام بالقبول فليس في أهل السنة من ينكره. وقد بين أن الاستواء معلوم كما أن سائر ما أخبر به معلوم ولكن

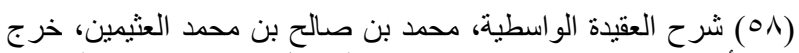

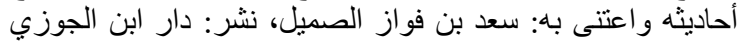

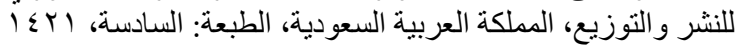
هـ ( ) (

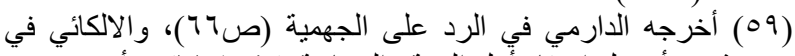

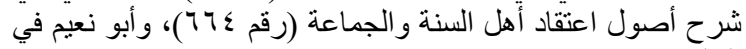

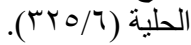


يقول منصور محمد حسب النبي: "الآية الكريمة: (وإن يوماً عند ربك كألف سنة مماتعدون) [الحج: \&V الأرض في يوم كان مقداره ألف سنة دماتعدون) [السجدة: 0 - 10] هاتان الآيتان قد تشيران إلى النسبية وانكماش الزمن بحيث أن الألف سنة انكمثت إلى يوم واحد على أساس المفهوم النسبي للزمن إذا اعتبرنا اليوم في هاتين الآيتين يوما من أيام الله التي لا يعلمها إلا هو سبحانه، لكنني أشير هنا أن أبحاثا جديدة شرعية وفيزيائية قد تمت لتقديم تفسير علمي جديد يؤدي إلى حساب سرعة الضوء من منطوق هاتين الآيتين إذا اعتبرنا ما يلي: 1- اليوم من أيامنا والسنة من سنيننا أي اليوم زمن دورة الأرض حول نفسها والسنة سنة قمرية كما في

$$
\text { قوله تعالى : " مماتعدون". }
$$

r- حيث إن اليوم لا يساوي ألف سنة مما نعد فإننا نستطيع أن نفهم أن الآية تشير إلى متحركين اثنين اتفقا في المسافة المقطوعة واختلفا في سرعة المسير، وقد أيد هذا المعنى جمهور من المفسرين وتمت الموافقة عليه في ندوة تحضيرية عقدتها هيئة الإعجاز العلمي في القرآن والسنة بمقر رابطة العالم الإسلامي وتشرفت بحضورها في ديسمبر 919 19 واتفق على تفسير آية السجدة: كما يلي: المسافة القصوى التي يقطعها الأمر الكوني في يوم أرضي تساوي تماما المسافة التي يقطعها القرر في مداره
وسنة رسول الله صلى الله عليه وسلم، فهي من الغيبيات التي لا تتلقى إلا عن طريق الوحي، فلا تضرب لها الأمثال ولا تشبه بشيء من خلق الله تبارك وتعالى، ولا يُتََرََّض لمحاولة تفسيرها أو التتبؤ بحقيقتها من خلال النظريات العلمية ولا القوانين الفيزيائية والفلكية. إن ما طرحته النظرية النسبية من بعض الافتراضات مثل ثبات سرعة الضوء، ونسبية الزمان والمكان، أدى إلى محاولة البعض لتثسير بعض صفات الله تعالى الفعلية(rآ) مثل سرعة أمر الله تبارك وتعالى، وزمن عروض الملائكة والروح إليه تبارك وتعالى الوارد في قوله تعالى: (تعرج الملائكة والروح إليه في يوم كان مقدار خمسين ألف سنة) [المعارج: ؛]، وتدبير الله تعالى للأمر وعروجه إليه الوارد في قوله تبارك وتعالى: (يدبر الأمر من السماء إلى الأرض في يوم كان مقداره ألف سنة مماتعدون ) [السجدة: 0]. ومقدار اليوم عند الله تبارك وتعالى، الوارد في قوله عز وجل: ( وإن يوماً عند ربك

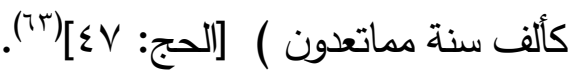

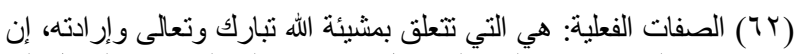

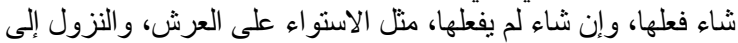

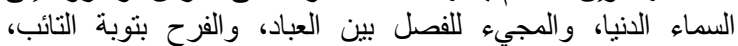

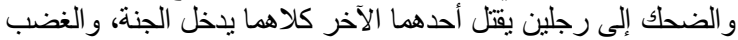

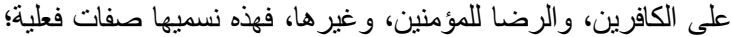
لأنها من فعله، وفعله يتعلق بمشيئته.

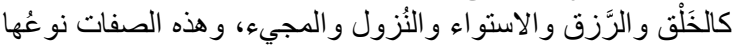

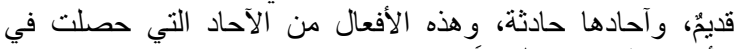
الأوقات التي شاء الله فعلَها فيها.

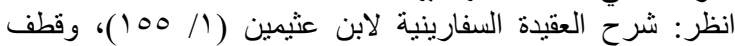

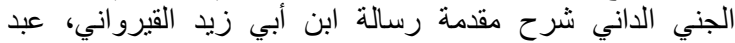

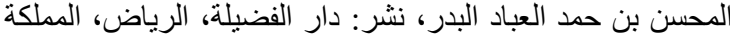

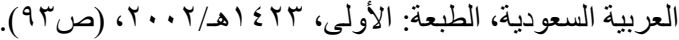

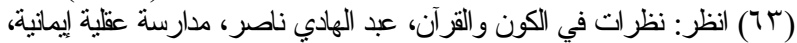

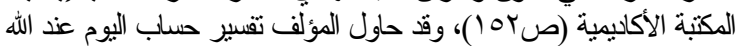
بألف سنة من أيامنامن خلا لول النظرية النسيية. 
يسلك من بين يديه ومن خلفه رصدا ) أي: يحفظونه بأمر اللهه|(70). وقد تكلم العلماء في الفرق بين اليوم الذي مقداره خمسين ألف سنة واليوم الذي مقداره ألف سنة، لكن لكن ليس بالنظر إلى النظرية النسبية، ولكن في المراد بهذين اليومين، قال العلامة الثنقيطي: پاعلم أولاً أن أبا عبيدة روى عن إسماعيل بن إبراهيم عن أيوب

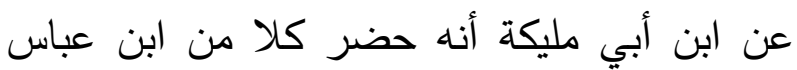

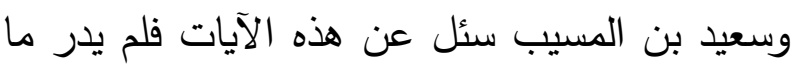
يقول فيها، ويقول: لا أدري.

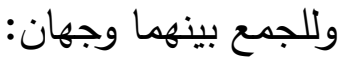
الأول: هو ما أخرجه ابن أبي حاتم من طريق سماك

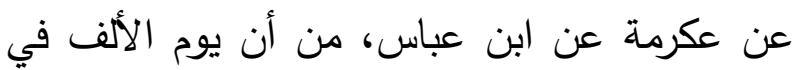

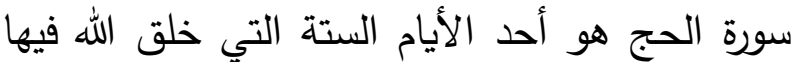
السموات والأرض، ويوم الألف في سورة السجدة، هو الإم السنه لهن مقدار سير الأمر وعروجه إليه تعالى، ويوم الخمسين ألثًا هو يوم القيامة. الوجه الثاني: أن المراد بجميعها يوم القيامة، وأن الاختلاف باعتبار حال المؤمن والكافر ، ويدل لهذا قوله تعالى: ( فذلك يومئذ يوم عسير، على الكافرين غير يسير )، ذكر هذين الوجهين صاحب الإتقان، والعلم عند الله تعالى" (74). لهنين

(70) تيسير الكريم الرحمن في تفسير كلام المنان، عبد الرحمن السعدي،

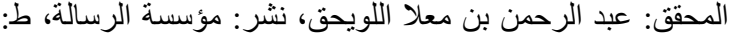

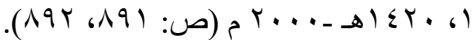

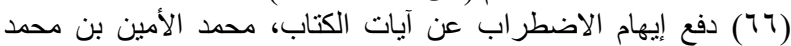

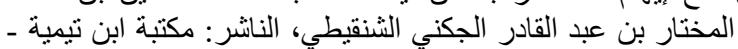

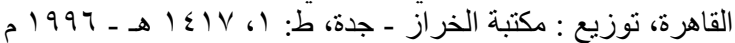

حول الأرض في ألف سنة قرية، وطبقًا لهذا التنسير فقد تم حساب السرعة القصوى للأمر الكوني في في لاني الذي اتضح أنه يسير بسرعة مساوية لسرعة الضوء

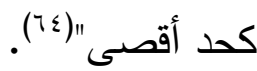
إن هذا الكلام تخرُصٌّ بغير علم؛ إذ أن هذه الأمور

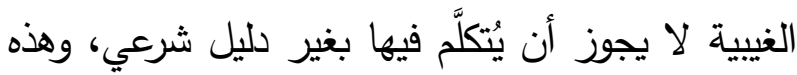
النظريات العلمية مهما بلغت فهي في النهاية أعمال

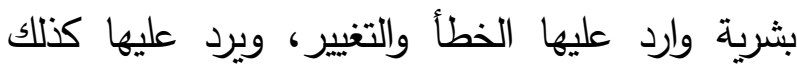
رجوع أصحابها عنها أو عن بعض أجزائها، فربط ذلك ولك ولك

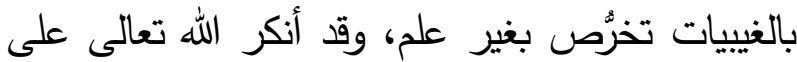

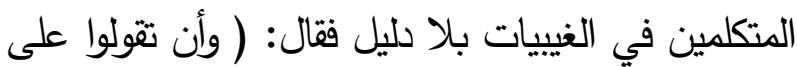
الله مالا تعلمون) ، وقال الله تعالى: ( قل إن أدري

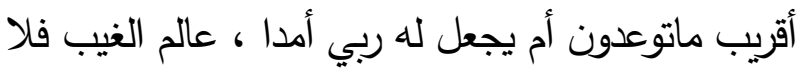

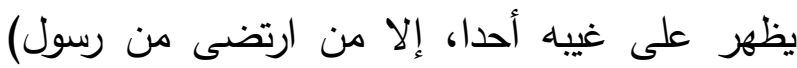

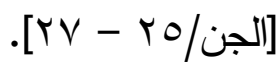
قال العلامة السعدي: ( أم يجعل له ربي أمداً) أي: غاية طويلة، فعلم ذلك عند الله. "عالم الغيب فلا يظهر على غيبه أحدا " من الخلق، بل انفرد بعلم الضمائر والأسرار والغيب، (إلا من من لفن

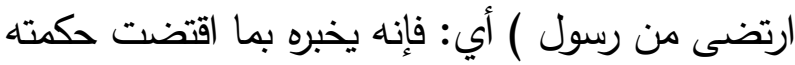
أن يخبره باه، وذلك لأن الرسل ليسوا كغيرهم، فإن الله أيدهم بتأييد ما أيده أحدًا من الخلق، وحفظ ما أوحاه إليهح حتى ييلغوه على حقيقته، من غير أن تتخبطهح الثياطين، ولا يزيدوا فيه أو ينقصوا، ولهذا قال: (فإنه

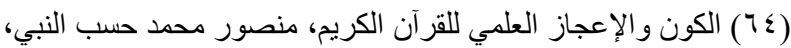

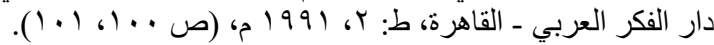




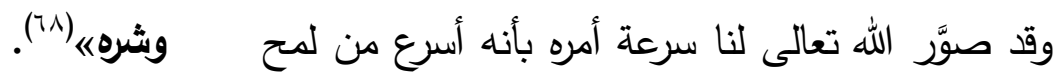

والملائكة خلقهم الله تعالى من نور؛ عن عائشة،

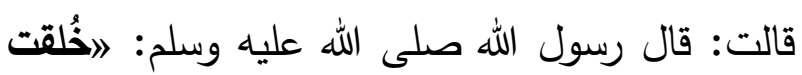
الملائكة من نور، وخلق الجان من مارج من نار، الهول وخلق آدم مما وصف لكمب(79).

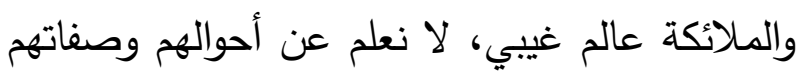

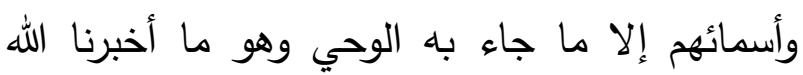
تعالى في كتابه ورسوله صلى الله عليه وسلم في سنته، قال العلامة ابن عثيمين رحمه الله: اوكيف

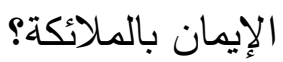
نؤمن بأنهم عالم غيبي لا يشاهدون، وقد يشاهدون، إنما الأصل أنهم عالم غيبي مخلوقون من نور مكلفون لاني بما كلفهم الله به من العبادات وهم خاضعون لله عز عز عزي وجل أتم الخضوع، ( يا أيها الذين آمنوا قوا أنفسكم

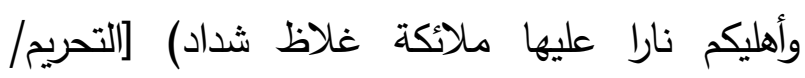
.$^{(v)} \ll[7$ ومن الإيمان بالملائكة الإيمان بإمكانية تمثلهم بصور

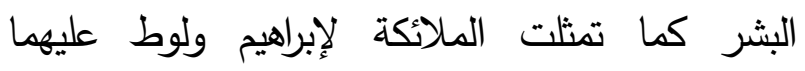
السلام(ال)"، وكما تمثَّل جبريل عليه السلام لمريم عليها السلام(rr)، وكما كان جبريل يأتي النبي صلى الله عليه

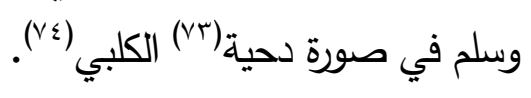

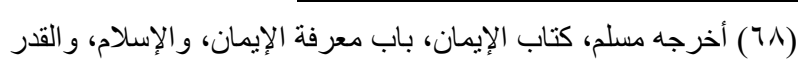

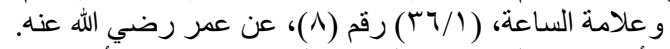

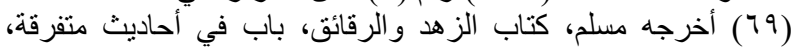

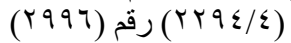

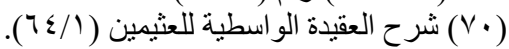

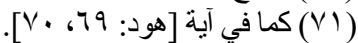
(VY) قال تعالى: ( فأرسلنا إليها روحنا فتمثل لها بشرا سويا ) ) [مريم: [l' (VT) الخندق وقيل أحد، ولم يثهد بدرا، وكان يضرب بن به المثل في حسن ينان

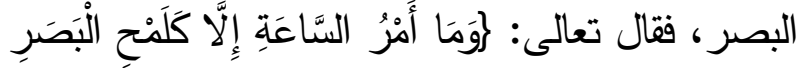

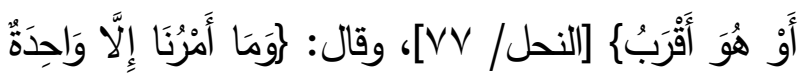
كَلَمْحِ بِالْبَصَرِ

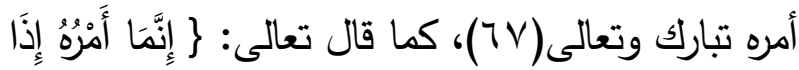

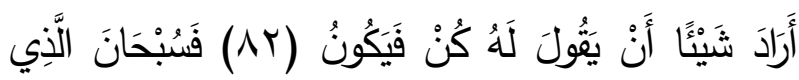

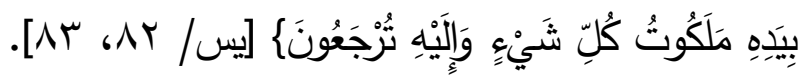

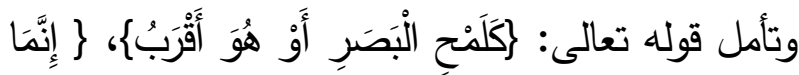

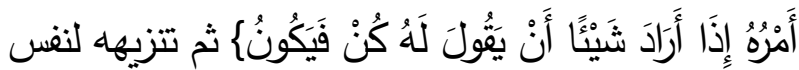
عن كل نقص وعيب، ومن ذلك أن يكون له شبيه

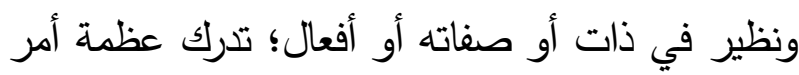
الله تعالى الذي لا يحيط به مخلوق، وليس له سرعة

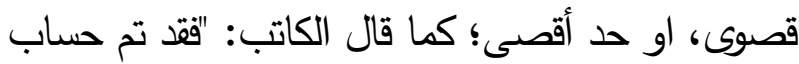
السرعة القصوى للأمر الكوني الذي اتضح أنه يسير بسرعة مساوية لسرعة الضوء كحد أقصى". المطلب الثاني: الرد على دعاوى العلماء في الربط بين النظرية النسبية وعقيدة الإيمان بالملائكة الإيمان بالملائكة من ضروريات الدين، فهو الركن الثاني من أركان الإيمان، قال الله تعالى: ( كل آمن بالله

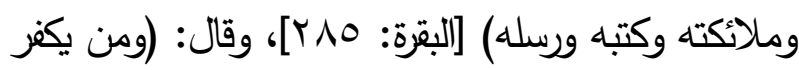
بالله وملائكته وكتبه ورسله واليوم الآخر فقد ضل

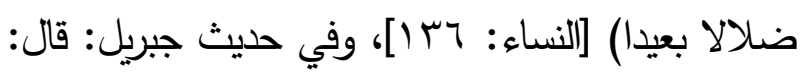

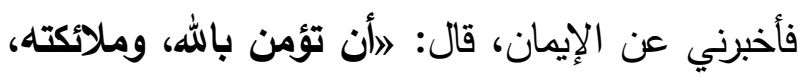
وكتبه، ورسله، واليوم الآخر، وتؤمن بالقدر خيره 
الطريق لقبول البديهيات قبولاً يتسم باستخدام الفكر ويقوم على أساس الاقتتاع بدلا من أن يكون تسليمًا

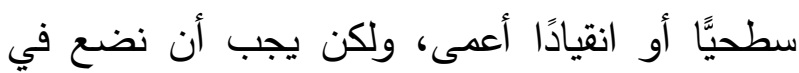

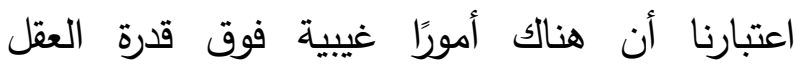

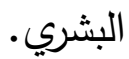

ولقد كان من نتائج اندماج المكان والزمان في النظرية النسبية أن اندمجت المادة والطاقة في أعظ قانون اكتشفه أينشتاين في القرن العشرين والذي الني ينص على أن: الطاقة = الكتلة X مربع سرعة

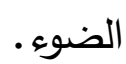

وبذلك فإن المادة قد تتحول إلى طاقة في عملية تدعى التمويج، وأن الطاقة قد تتحول إلى مادة في عملية تدعى التجسيد، طبقا لقانون أينشتاين، وبهذا

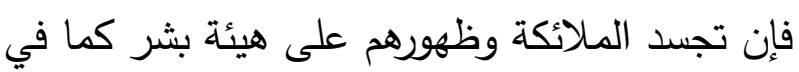
تجسد جبريل للعذراء مريم وتجسده لسيدنا محمد عليه الصلاة والسلام على هيئة رجل اسمه دحية الكلبي

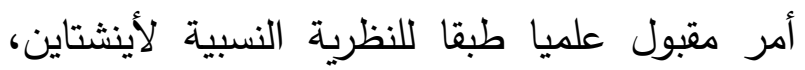
وصدق الله العظيم بقوله تعالى في سورة مريم:

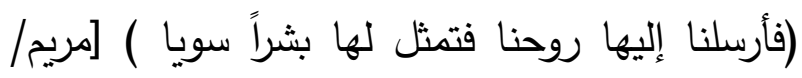
.$^{(V T)} \ll[1 \mathrm{~V}$ إن هذا الذي يدعي إنه يريد إثباته بالنظريات العلمية

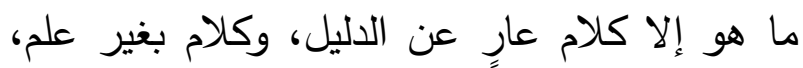

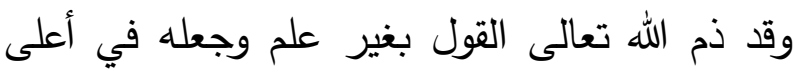
مراتب لتحريم فقال: (وأن تقولوا على لعيل الله مالا تعلمون) [الأعراف/ rr]
ومن الانحراف في العقيدة محاولة تفسير بعض ما

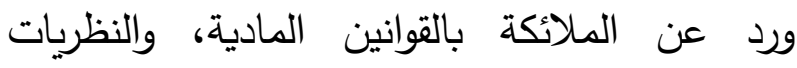
العلمية، مثل تفسير بعض خصائص الملائكة من خلال بعض ما توصلت إليه النظرية النسبية من افتراضات، مثل تفسير سرعة حركة الملائكة في

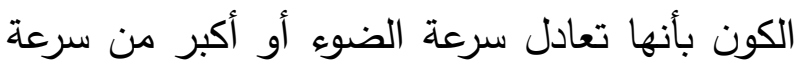

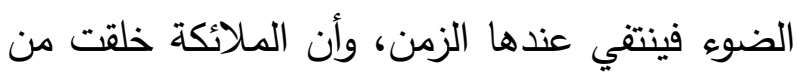
نور وهو الضوء، وتفسير تصور الملائكة في صورة

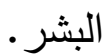
يقول منصور محمد حسب النبي: الومن المعروف طبقًا للنظرية النسبية أنه لو وجد كائن له سرعة أكبر

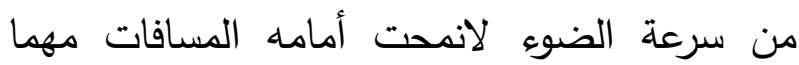
عظد، ولأمكنه قطعها في غير زمن! وهذا قد يفسر

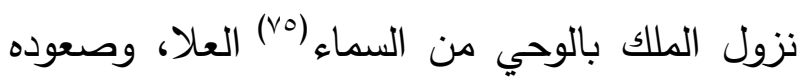
إليها في غير زمن بأن الملك كانت سرعته أكبر من سرعة الضوء!... والملائكة قد تسير بسرعة الضوء لضوان

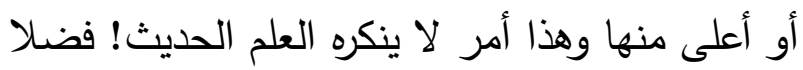

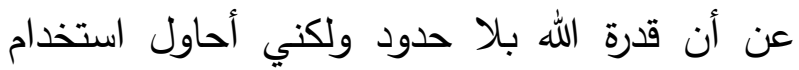
الأسلوب العلمي للاستدلال على إمكانية حدوث مثل بلان هذه السرعات. وليس هذا ضعفا في الإيمان ولكنه

الصورة، وكان جبريل عليه السلام ينزل على صورته، ثم نزل

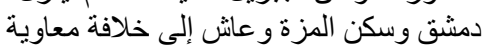

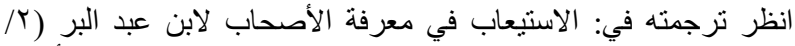

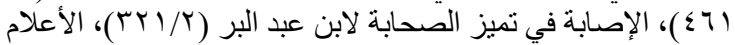

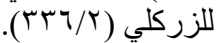

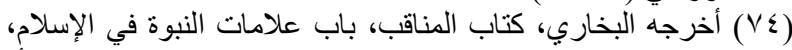

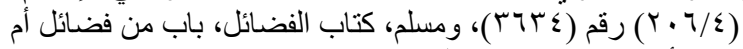

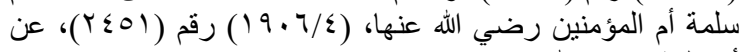
أم سلمة رضي الله عنها.

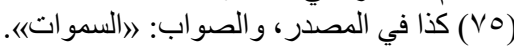


يسلم لله هو الكتاب والسنة.

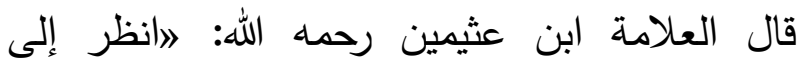
الملائكة تتزل لقبض روح الإنسان في المكان نفسه؛ كما قال تعالى: ( ونحن أقرب إليه منكم ولكن لا تبصرون) [الواقعة/10] ومع ذلك؛ لا نبصرهم. وملك الموت يكلم الروح، ونحن لا نسمع. وجبريل يتمثَّل أحيانًا للرسول عليه الصلاة والسلام، ويكلمه بالوحي في نفس المكان، والناس لا ينظرون ولا يسمعون. فعالم الغيب لا يمكن أبدًا أن يقاس بعالم الشهادة، وهذه من حكمة الله عَزَّ وَجَلَّ؛ فنفسك التي في جوفك ما تدري كيف تتعلق ببدنك؟! كيف هي موزعة على البدن!! وكيف تخرج منك عند النوم؟! هل تحس بها عند استيقاظك بأنها ترجع؟! ومن أين تدخل لجسمك!! فعالم الغيب ليس فيه إلا التسليم، ولا يمكن فيه القياس إطلاقًا ه(v9).

وليس الإيمان بالغيب إيمانًا سطحيَّا ولا انقيادًا أعمى، كما ذكر الكاتب، وإنما هو يقين بالقلب، نابع من الإيمان بصدق النبي صلى الله عليه وسلم في كل ما جاء باء عن الله تبارلك وتعالى، فهل كان إيمان المؤمنين قبل اكتشاف هذه النظريات إيمانًا سطحيًّا وانقيادًا أعمى؟ فأبو بكر الصديق رضي الله عنه لما جاءه المشركون يشككونه في صدق النبي صلى الله عليه وسلم في

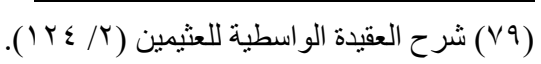

قال ابن القيم: افرتَّب المحرمات أربع مراتب، وبدأ بأسهلها وهو الفواحش، ثم ثنَّى بما هو أثد تحريمًا منه وهو الإثث والظلم، ثم ثلث بما هو أعظد تحريما منهما وهو الشرك به سبحانه، ثم ربع بما هو أثد تحريما من ذلك كله وهو القول عليه بلا علم، وهذا يعم القول عليه سبحانه بلا علم في أسمائه وصفاته وأفعاله وفي دينه وشرعهه (Vv). وحقيقة النور الذي خُلقت منه الملائكة هل لله علاقة بالضوء الذي تقاس به السرعة عند الفزيائيين أم لا؛

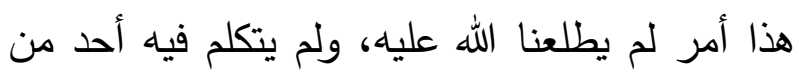
أهل العلم بيان فوق أنه كما قال النبي صلى الله عليه

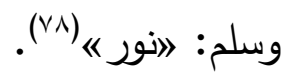

وأما ربطه بين تصور الملائكة في صورة البشر واندماج المادة والطاقة وقوله: 》افان المادة قد تتحول إلى طاقة في عملية تدعى التمويج، وأن الطاقة قد تتحول إلى مادة في عملية تدعى التجسيد، طبقا لقانون أينشتاين، وبهذا فإن تجسد الملائكة وظهورهم على هيئة بشر كما في تجسد جبريل للعذراء مريم وتجسده لسيدنا محمد عليه الصلاة والسلام على هيئة رجل اسمه دحية الكلبي أمر مقبول علميا طبقا للنظرية النسبية لأينشتاينه، فهذا كلام في أمر غيبي لا يمكن معرفته إلا بالوحي وهو خلق الملائكة وحركتهم ووظائفهم، بين دليل، والدليل الوحيد الذي

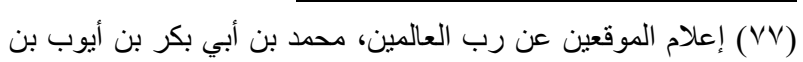

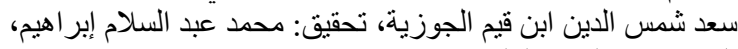

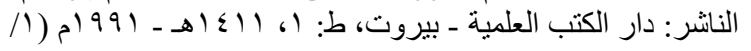
(r) (VN) https://www.islamweb.net/ar/fatwa//9v011 
والإيمان بالغيب يقتضي التسليم والتصديق من عدم

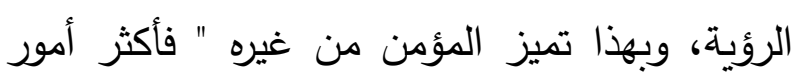

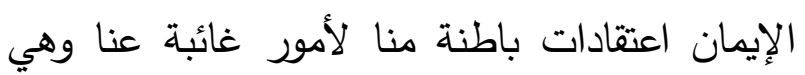
أعلى صفات أهل الإيمان \}الذين يؤمنون بالغيب الإنيان

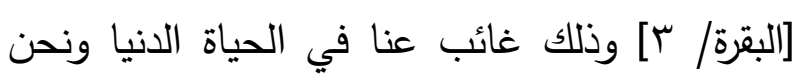
نعلمه عن الله علم اليقين فإذا خرجنا من هذه الدار

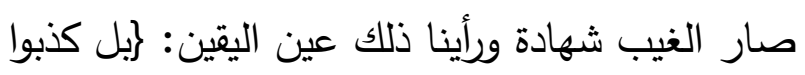
بما لم يحيطوا بعلمه ولما يأتهم تأويله كذلك كذب التبن التبل الذين من قبلهم فانظر كيف كان عاقبة الظالمين\{

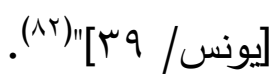
المطلب الثالث:

الرد على دعاوى العلماء في الربط بين النظرية النسبية ووقوع معجزات الأنبياء

الإيمان بالأنبياء والرسل من أصول الإيمان، وهو

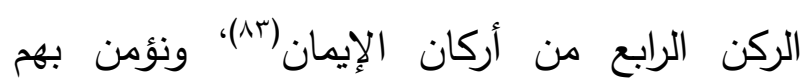
إجمالًا وبمن جاء ذكرهم في الوحيين على وجه الإنهان التقصيل. ومن الإيمان بالأنبياء الإيمان بأن الله تعالى أيدهم

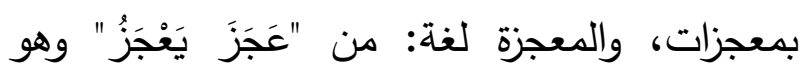

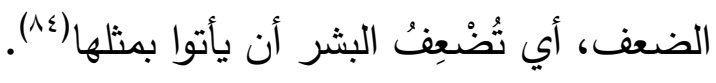

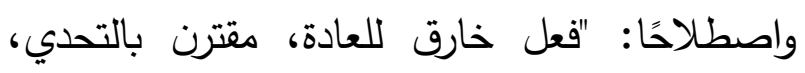

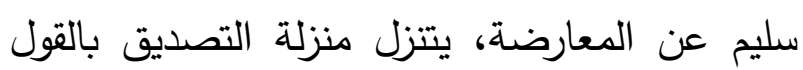

$$
\text { من حيث القرينة"(^o). }
$$

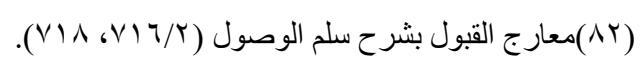
(AT)

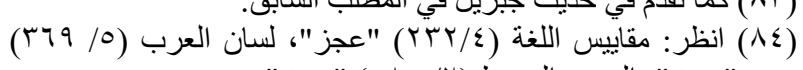

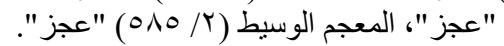
(10) انظر: الملل والنحل، لأبي الفتح محمد بن عبد الكريم الكريم بن أبى بكر
خبر الإسراء، دفع شكوكهم بيقينه وتصديقه التام فقد

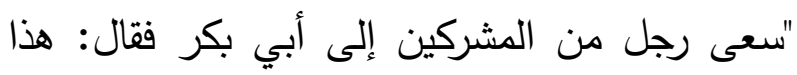

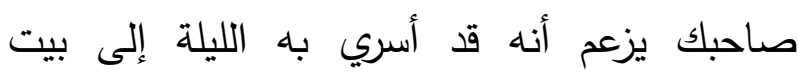
المقدس ثم رجع من ليلته فقال أبو بكر : أو قال ذلك؟ بله

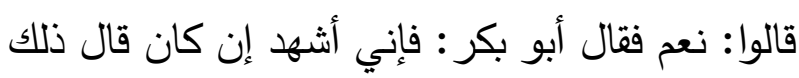

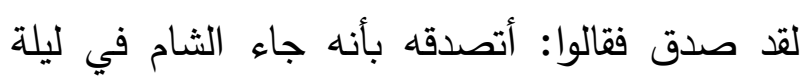
واحدة ورجع قبل أن يصبح؟ قال أبو بكر : نعم إني

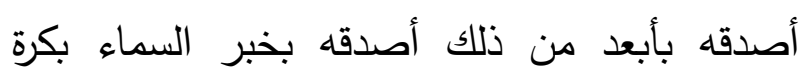

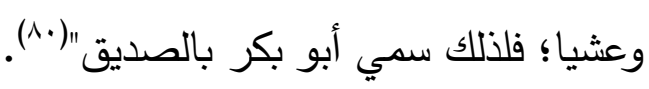
وكذلك خبر خزيمة بن ثابت رضي الله عنه لما شهر بل بله للنبي صلى الله عليه وسلم أنه ابتاع من الأعرابي

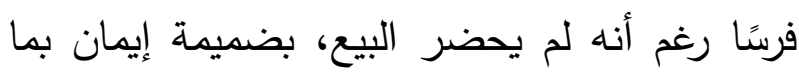

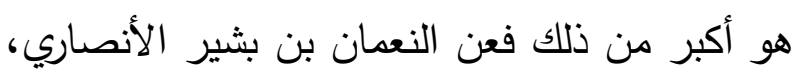

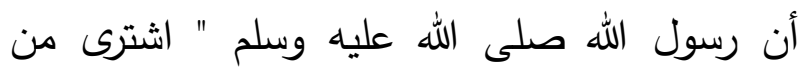
أعرابي فرسا فجحده الأعرابي فجاء خزيمة بن ثابت

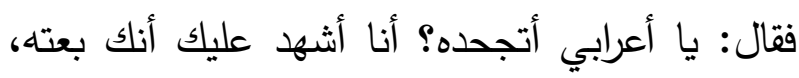

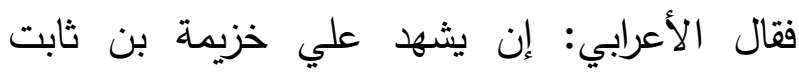
فأعطني الثمن، فقال رسول الله صلى الله عليه وسلم:

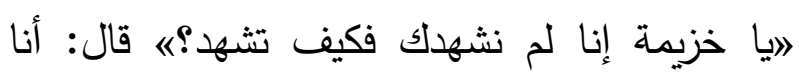

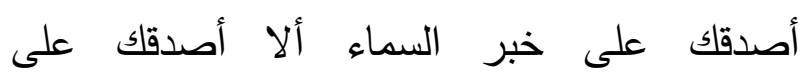
الأعرابي، فجعل رسول الله صلى الله عليه وسلم شهادته بشهادة رجلين (').

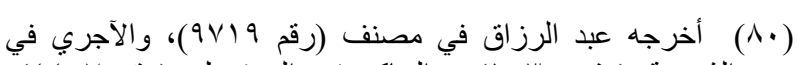

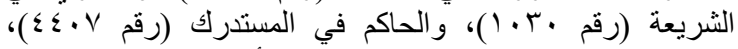
وصححه الحاكم وو افقه الذهبي، وصححه الألباني في الصحيحة رقم . ( $(\mathrm{r} \cdot \mathrm{T})$

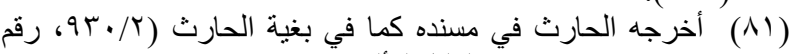

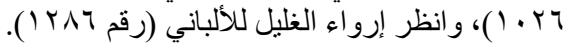


من سرعة الضوء لانمحت أمامه المسافات مهما عظمت، ولأمكنه قطعها في غير زمن! وهذا قد يفسر

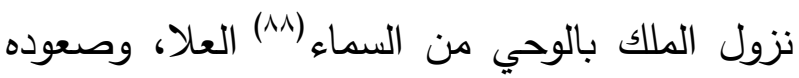

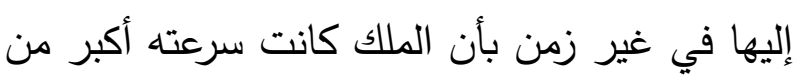
سرعة الضوء! كما يفسر أيضًا معجزة الإسراء والمعراج التي حدثت تكريمًا للرسول سيدنا محمد الصناء صلى الله عليه وسلم، الذي رافق جبريل في هذه الرحلة الثهيرة المذكورة بالكتاب والسنة كما في قوله تعالي مشيرًا إلى الإسراء: أسبحان الذي أسرى بعبده

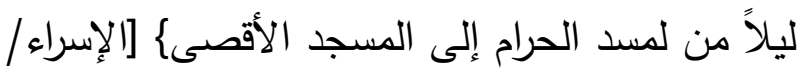

وقوله تعالى مشيرًا إلى المعراج: كولقد رواه نزلة

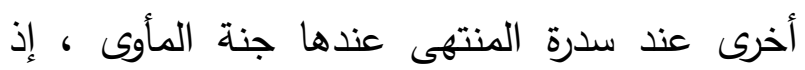

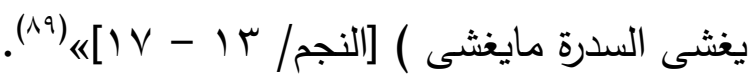

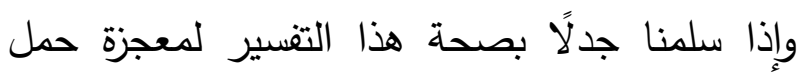
عرش بلقيس، والإسراء والمعراج، فأين ذهبت الطاقة

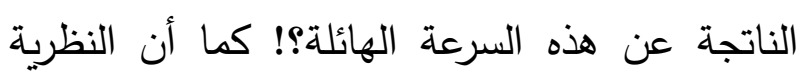
النسبية تقول بعدم أمكانية حركة الأجسام المادية أكثر من سرعة الضوء، وأن المكان نفسه ينعدم عند سرعة الضوه، ويصبح لا يسع شينًا (·9).

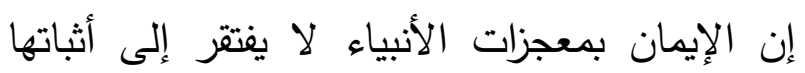

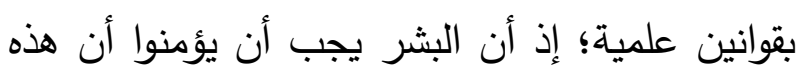

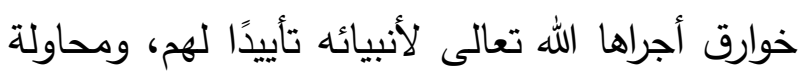

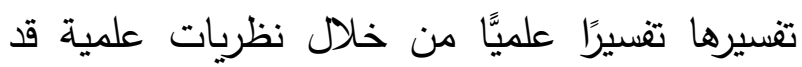

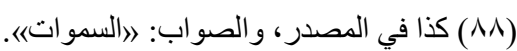

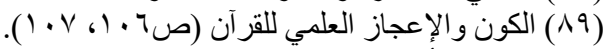

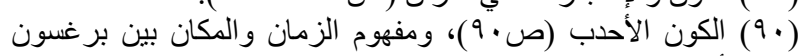
و أينشتاين (ص (1) (1) (1) . (1).
قال ابن الوزير : 》النبوات وآياتها الْبِيَّةَة ومعزاتها

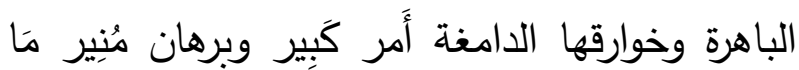

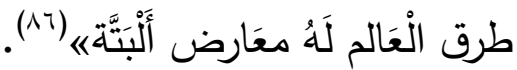
ومحاولة تقسير هذه المعجزات من خلال القوانين العلمية والنظريات الفزيائية والفلكية خطأ ظاهر ، إذ

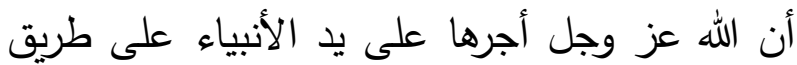

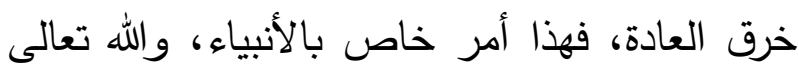
لا يعجزه شيء سواء جرى وفق قوانين الكون أو خرق الله به تلك القوانين. كما أن هذه القوانين بشرية يجري عليها الخطأ، ويطرأ عليها التعديل، وكثيرًا ما يعيد الباحثون النظر فيها ويستدرك السابق على اللاحق منهم، فإذا ما ظهر من

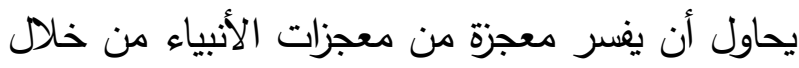
قانون فيزيائي مثلًا، ثم ظهر بعد ذلك خطأ ذلك القانون فهذا سيؤدي إلى الطعن في هذه المعزة من المشككين.

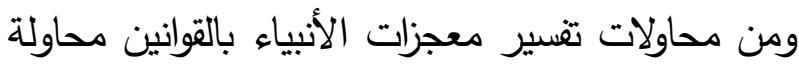
ربط بعض المعجزات بالنظرية النسبية مثل معجزة الإنراء والمعراج، ومعجزة حمل عرش بلقيس من اليمن إلى بيت المقدس ليَمَتُك أمام سليمان عليه السلام قبل أن يرتد إليه طرفه (^V). يقول منصور محمد حسب النبي: اومن المعروف طبقًا للنظرية النسبية أنه لو وجد كائن له سرعة أكبر

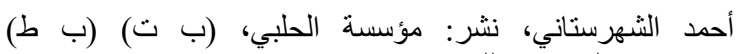

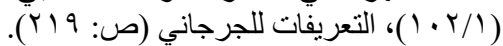

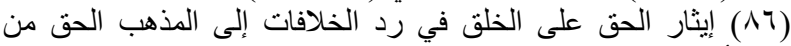

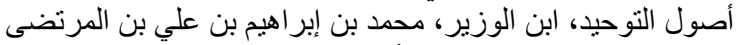

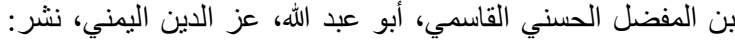

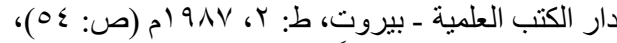

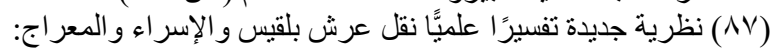
http://alfetn.net/vbr/showthread.php?t=0ץч
} 
كالزمان والمكان والسرعة والكتلة والجاذبية والتسارع، ولكنها تنظر إلى هذه الأمور بوجهة نظر أخرى.

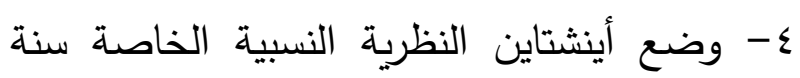
ه.9 ام، وهى تدرس حركة الأجسام المتحركة بسرعة منتظمة في خط مستقيم.

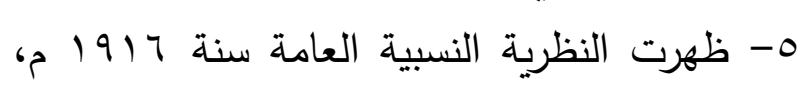
وهي تدرس حركة الأجسام المتحركة بتسارع.

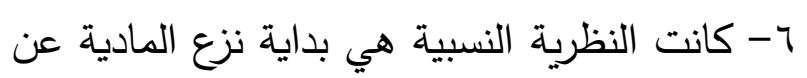
المادة، وذلك بربطها بين الكتلة والطاقة. - V كل نقطة فيه حادث من الحوادث لها مكان وزمان، يحدد موضعها. ^- نظرت النظرية النسبية إلى الحوادث على أنها. نسبية فهي نسبية في حدوثها ومكانها وزمانها.

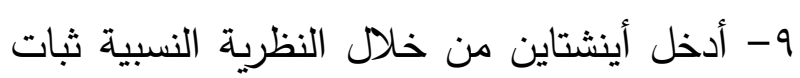
سرعة الضوه، فلا يوجد شيء في الكون يمكن أن أن تصل سرعته لأكبر من سرعة الضوه. • 1- أدخل أينشتاين الزمن كبعد رابع للأبعاد

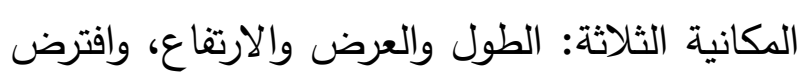
أيضًا أن الزمان نسبي كالمكان. 11- فكرة التزامن التي افترضتها الفيزياء الكلاسيكية كفكرة مطلقة، خرج أينشتاين من خلال النظرية النسبية أنها نسبية أيضًا وليست مطلقة. r ا - تقترض النظرية النسبية نسبية المكان فلا يوجد ما يسمى بالمكان المطلق. rا - نظرت النسبية إلى طبائع الأشياء على أنها لهان
يكون الباحث أو الداعية لم يحط بها علمًا؛ لا يعتبر من قبيل الإعجاز العلمي بل هو في الحقيقة إهدار لقدسيتها. وخلاصة القول: مهما بلغ العلم الحديث من

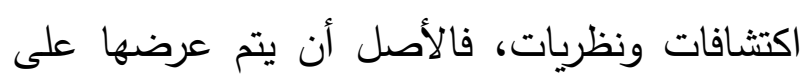

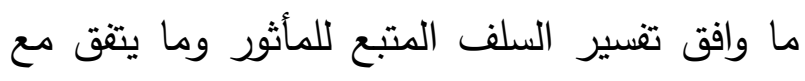
قواعد اللغة العربية، فإن وافق اكتثاقهر ما قاله

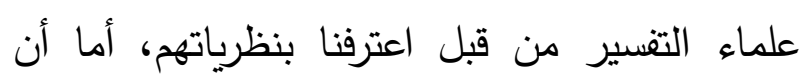
نكلف النص تفسيراً جديدا ونلويه حتى نجعله تابعاً لاكتشاف علمي فليس هذا منهج صحيح، حيث جعل الثابت تابعاً وهو النص الثرعي للمتغيرات وهي الاكتشافات العلمية والنظريات، وعلوم البشر قدابت تتغير بعد فترة .

\section{الخاتمة}

الحمد الله والصلاة والسلام على رسول الله وبعد: في ختام هذا البحث فقد توصلت لعدة من النتائج والتوصيات هي: 1 - ألبرت أينشتاين عالم طبيعة يهودي ألماني، ولد

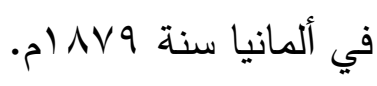
r- لا يمكن تقسير إسهامات أينشتاين في علم

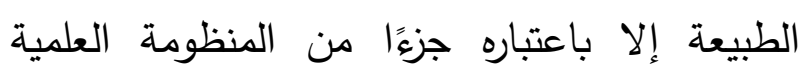

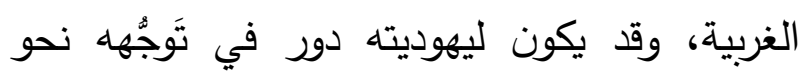
النسبية، ولكن المنظومة العلمية الغربية ككل تظل العنصر المحدد النهائي. ب- النظرية النسبية: نظرية فيزيائية (طبيعية) تبحث النيائ في مواضيع من التي تبحثها الفيزياء العادية، 
من اليمن إلى بيت المقدس لَيَنْتُل أمام سليمان عليه السلام قبل أن يرتد إليه طرفه.

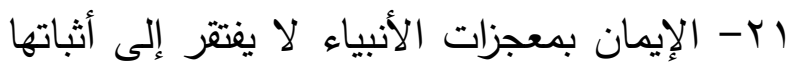
بقوانين علمية.

آY- القوانين الطبيعية بشرية يجري عليها الخطأ ويطرأ عليها التعديل وكثيرًا ما يعيد الباحثون النظر لئريا فيها ويستدرك السابق على اللاحق منهم.

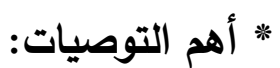

ا- تناول بقية الأبواب الشريعة التي أُدخل فيها

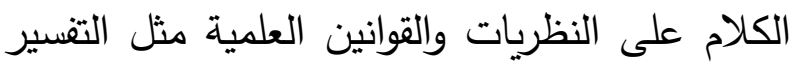

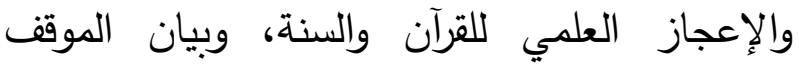
الثرعي من تطبيق تلك النظريات في فهم الأمور

الشرعية فيها.

r- العناية بنشر المنهج الصحيح في فهم العقيدة الإسلامية وهو الوقوف على ما جاء في الكتاب والسنة وبفهم القائم على التسليم الإيمان والتسليم. r- دراسة القوانين الطبيعية والنظريات الرائجة عند الكتاب والمفكرين الإسلاميين وبيان موقف الإسلام منها.

فهرس المصادر والمراجع

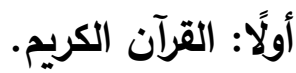

ثانيًا: المصادر والمراجع: المران

ا. إعلام الموقعين عن رب العالمين، محمد بن أبي بكر بن أيوب بن سعد شمس الدين ابن قيم الجوزية، تحقيق: محمد عبد السلام إبراهيم، الناشر: دار الكتب العلمية - ييروت، ط: ا، الإيه -
نسبية تتغير بتغير الحركة والسرعة. ـ ا- جاءت النظرية النسبية تثبت بطلان نظرية المصادفة إذ أنها بينت أن العالم محكوم بقوانين ونظام محكم لا يتخطاه. 10- وطريق علم صفات الله تبارك وتعالى عند أهل السنة والجماعة إنما هو النَّقلُ، فلا سبيل لمعرفة صفات الله تبارك وتعالى إلا بما ورد في كتاب الله أو صح في سنة رسول الله صلى الله عليه وسلم.

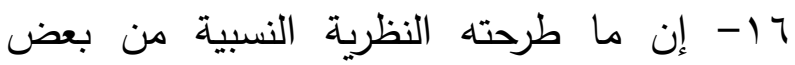
الافتراضات مثل ثبات سرعة الضوه، ونسبية الزمان

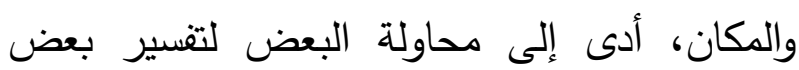
صفات الله تعالى الفعلية. IV الملائكة عالم غيبي، لا نعلم عن أحوالهم وصفاتهم وأسمائهم إلا ما جاء با الوحي. 11- ومن الانحراف في العقيدة محاولة تفنير بعض ما ورد عن الملائكة بالقوانين المادية، والنظريات العلمية. 9 19- محاولة تفسير معزات الأنبياء من خلال

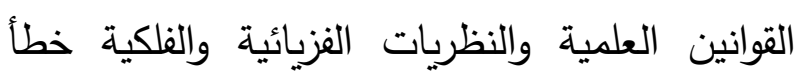
ظاهر، إذ أن الله عز وجل أجرها على يد الأنبياء

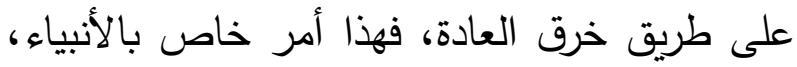
والله تعالى لا يعجزه شيء سواء جرى وفق قوانين الكون أو خرق الله به تلك القوانين. • ץ- من محاولات تفسير معجزات الأنبياء بالقوانين

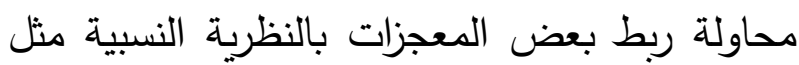
معجز الإسراء والمعراج، ومعجزة حمل عرش بلقيس 
r. الإكليل في المتثابه والتأويل، لثيخ الإسلام ابن 9 9. تيسير الكريم الرحمن في تفسير كلام المنان، تيمية، خرج أحاديثه وعلق عليه: محمد الثيمي عبد الرحمن السعدي، المحقق: عبد الرحمن بن معلا

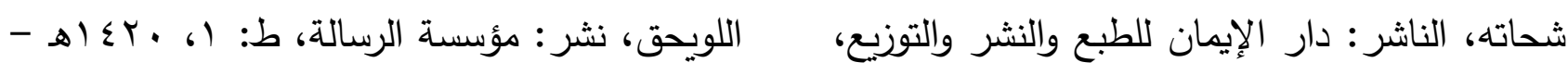

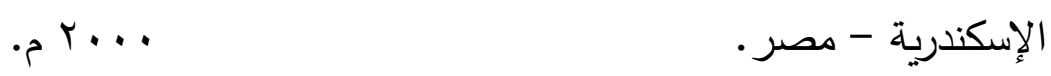

r. إيثار الحق على الخلق في رد الخلافات إلى ا.حلية الأولياء، أبو نعيم أحمد بن عبد الله بن

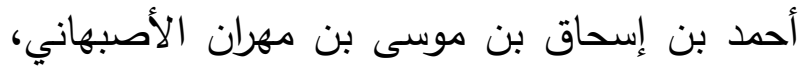

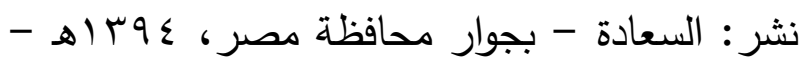
$.019 \vee \varepsilon$

11 (ـ دستور العلماء = جامع العلوم في اصطلاحات الفنون، القاضي عبد النبي بن عبد الرسول الأحمد

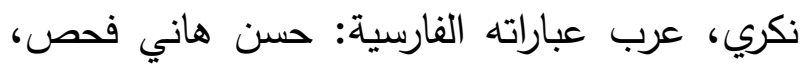

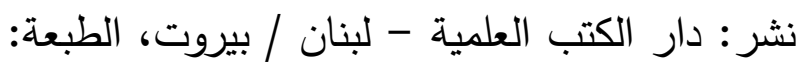

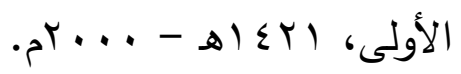
المذهب الحق من أصول التوحيد، ابن الوزير، محمد لهد بن إبراهيم بن علي بن المرتضى بن المفضل

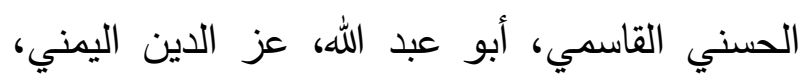
نشر: دار الكتب العلمية - بيروت، ط: rا $.019 \Lambda \mathrm{V}$ ع. أينشتاين حياته وعالمه، والتر إيزاكسون، ترجمة

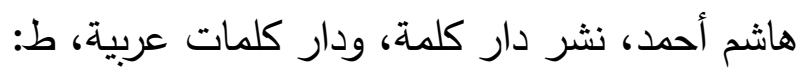

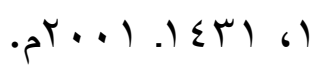
r ا. دفع إيهام الاضطراب عن آيات الكتاب، محمد 0. أينشتين والنسبية، د. مصطفى محمود، دار الأمين بن محمد المختار بن عبد القادر الجكني الشنقيطي، الناشر : مكتبة ابن تيمية - القاهرة،

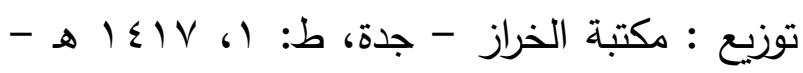
. 1997 با اـ الرد على الجهمية للدارمي، عثمان بن سعيد بن

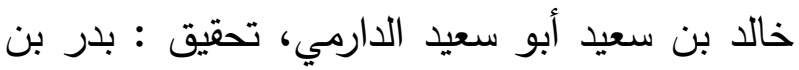

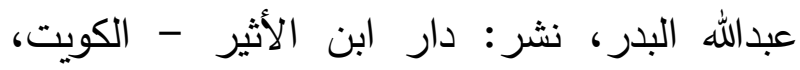

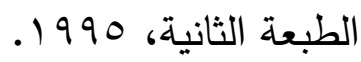
ـ ا. الزمان والمكان اليوم، مجموعة من المفكرين، ترجمة محمد وائل بشير الأتاسي 1. شرح أصول اعتقاد أهل السنة والجماعة، أبو لتئي القاسم هبة الله بن الحسن بن منصور الطبري الرازي

T. التدمرية: تحقيق الإثبات للأسماء والصفات وحقيقة الجمع بين القدر والثرع، تقي الدين ابن تيمية، المحقق: د. محمد بن عودة السعوي، نشر:

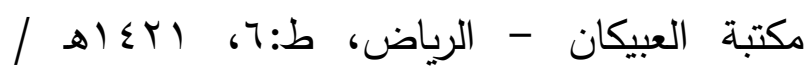
. V. التعريفات، علي بن محمد بن علي الزين

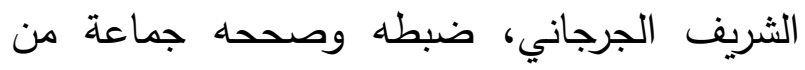
العلماء بإشراف الناشر، نشر: دار الكتب العلمية

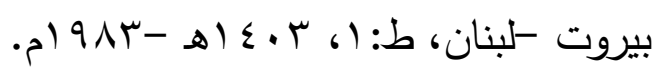
A. تهذيب اللغة: محمد بن أحمد بن الأزهري

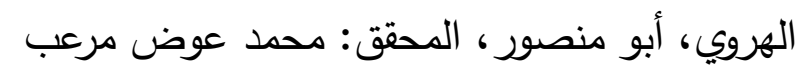


اللالكائي، تحقيق: أحمد بن سعد بن حمدان الحميد، دار التكوين للتأليف والطباعة والنشر، ط:

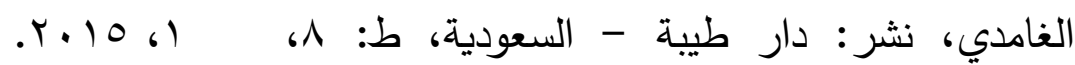
rr. العقيدة الواسطية: اعتقاد الفرقة الناجية المنصورة . إلى قيام الساعة أهل السنة والجماعة، لابن تيمية، 17 ا.شرح العقيدة السفارينية محمد بن صالح بن الهن القاسم بن محمد ابن تيمية الحراني الحنبلي

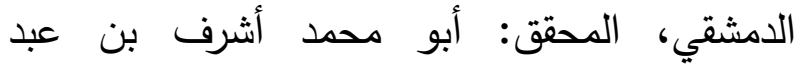
محمد العثيمين، نشر: دار الوطن للنشر، الرياض، المقصود، نشر: أضواء السلف - الرياض، الطبعة:

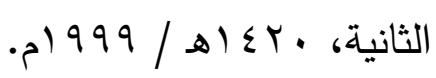
؟Y. العلمانيّة - نشأتهَا وتطوّرهَا وآثارُهَا في الحيَّاة الإسلاميَّة المُعَاصِرَة، سفر الحوالي، دار الهجرة.

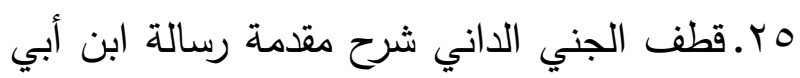

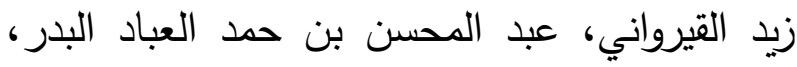
نشر: دار الفضيلة، الرياض، المملكة العربية

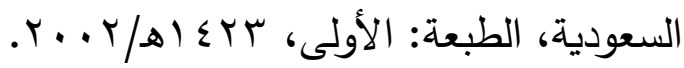

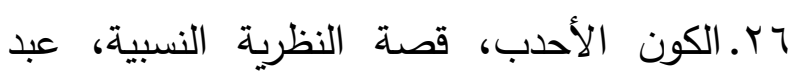

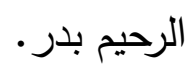

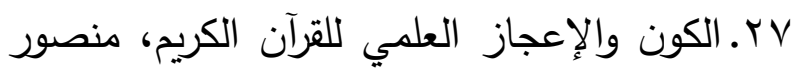
محمد حسب النبي، دار الفكر العربي - القاهرة، ط: . 1991 ( 19

人 Y. الله يتجلى في عصر العلم، تأليف: نخبة من العلماء الأمريكيين بمناسبة السنة الدولية لطبيعيات الأرض، أشرف على تحريره: جون كلوفر مونسيما، ترجمة: الدكتور الدمرداش عبد المجيد سرحان، راجعه وعلق عليه: الدكتور محمد جمال الدين لردئ الفندي، الناشر: دار القلم، بيروت - لبنان العقيدة

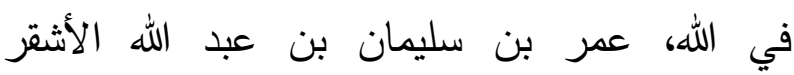


العتيبي، الناشر: دار النفائس للنشر والتوزيع، الحلبي، (ب ت) (ب ط).

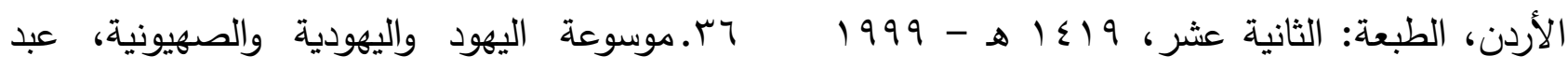

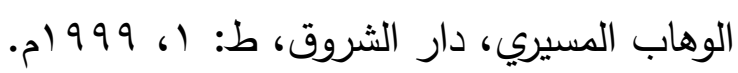

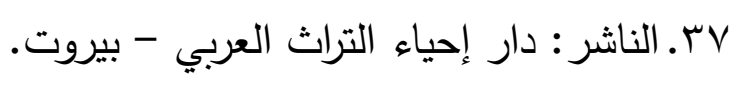

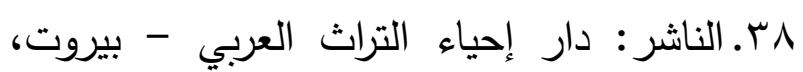

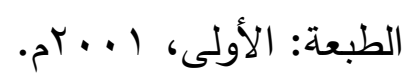

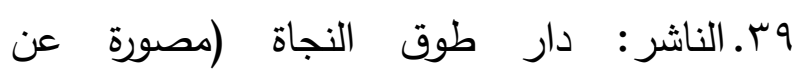

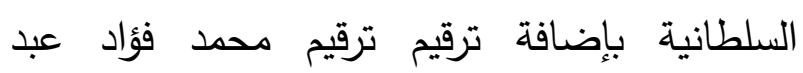

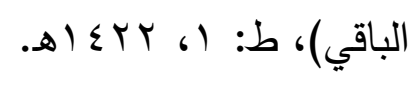

9 \%. المحكم والمحيط، لابن سيده، أبو الحسن علي بن إسماعيل بن سيده المرسي، المحقق: عبد الحميد

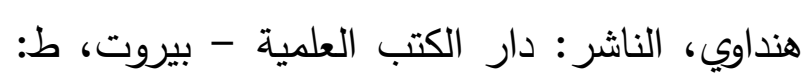
) ،

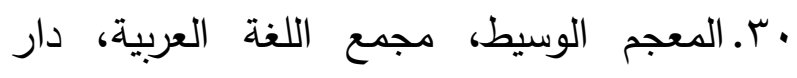

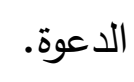
•ع.نحو فلسفة العلوم، النظريات الذرية والكوانتم والنسبية، د عبد الفتاح مصطفى عطية.

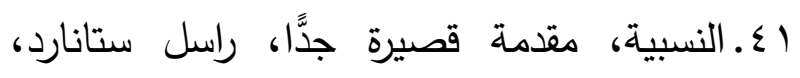
ترجمة محمد فتحي خضر، مؤسسة هنداوي للتعليم

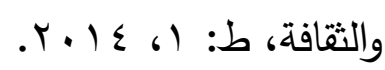

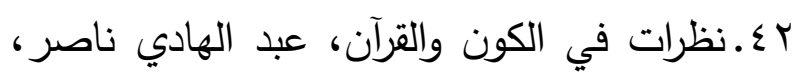
مدارسة عقلية إيمانية، المكتبة الأكاديمية.

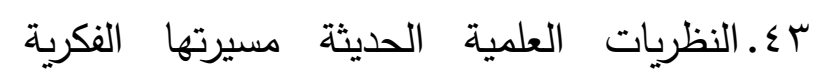

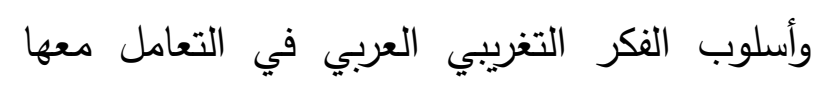

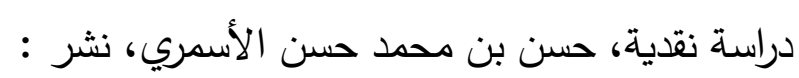

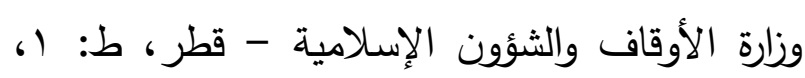

$$
\text { r. r - r }
$$

؟ ـ.النظرية النسبية الخاصة، على مصنى مصنى مشرفة، مطبعة لجنة التأليف والترجمة والنشر،

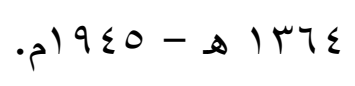

هـ.نونية ابن القيم، الكافية الثافية، محمد بن أبي بكر بن أيوب بن سعد شمس الدين ابن قيم الجوزية، 
r. مبدأ التكافؤ في النظرية النسبية العامة، أمجد خرواط: https://www.science.org.ly// $\left./ \Upsilon_{-}\right) \uparrow \wedge \varepsilon$

ع. ـ موقع الموسوعة الحرة "wikipedia". ه. ماهية النور الذي خلقت منه الملائكة، على موقع إيلام ويب:

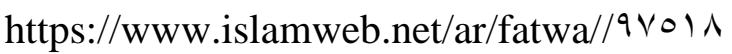
7. نظريـة جديد تفسيرًا علميًا نقل عرش بلقيس والإسراء والمعراج: http://alfetn.net/vb3/showthread.php?t=5364

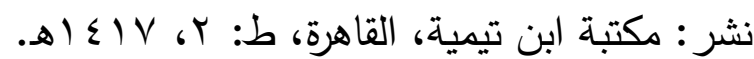
7٪.ولسان العرب، محمد بن مكرم بن على، أبو الفضل، جمال الدين ابن منظور الأنصاري الرويفعى الإفريقى، دار صادر - بيروت، ط:س، ع (1 أ هـ. ثانيًا: المواقع والمجلات: ا. المكان والمصطلحات المقاربة له - دراسة مفهوماتية، د غيداء أحمد سعدون شلاش، مجلة أبحاث كلية التربية الأساسية، المجلد ا(1، العدد ب. r. ما هو مبدأ التكافؤ؟ وكيف يقود الى النسبية العامة؟.. بقلم: معز جعفر كمال الدين: http://www.sudanile.com/ / T T 1 r 


\title{
Impact of Relativity on Some Beliefs; Presentation and Criticism:
}

\author{
Asma Salem Ahmed bin Afif \\ Co-Professor, Doctrine And Contemporary \\ Schools of Intellect, Shareea'h And Islamic Studies \\ King Abdulaziz University / Jeddah
}

\begin{abstract}
Impact of Relativity on Some Beliefs; Presentation and Criticism has discussed the broad acceptance that Relativity has encountered not only for researchers in the natural sciences, but also for those interested in religion as monks and warriors of atheism considered it to be an advocate of religion and belief in the existence of God (Allah).

Relativity has also become popular among those interested in research in Islamic sciences as they began to interpret the verses of the Koran and the Prophet's Hadiths and some of the unseen and beliefs through the findings of Relativity.

The study tries to discuss this orientation and its impact on beliefs and assumptions and to show the correct face in dealing with beliefs and unseen.

The research has included: an introduction and three chapters, within the introduction, the researcher has pointed out the importance of the research topic, the reasons why it has been chosen and the research methodology.

The first chapter has introduced Albert Einstein of the Relativity Theory: his life, his perspective with regards to the Relativity Theory and the rules of this theory.

In the second chapter, the research has discussed the approaches of some of the Muslim scientists and intellectuals.

Within the third chapter, the research has criticized the perspective of some scientists and intellectuals which states the Relativity Theory among some of the beliefs according to the doctrine of the Sunnis, as it includes some demands:

The first demand discusses the predecessors rule in regards to handling occult matters.

The second one is: The rebuttal to scientists preaching of matching the Relativity Theory with The Believing in Angels Doctrine.

And the third is: The rebuttal to scientists preaching of matching the Relativity Theory with the manifestation of the prophets's Miracles.

Finally, the conclusion addressed the main findings and recommendations of the study.
\end{abstract}

